Max-Planck-Institut für demografische Forschung

Max Planck Institute for Demographic Research

Konrad-Zuse-Strasse $1 \cdot$ D-18057 Rostock · GERMANY

Tel +49 (0) 3812081 - 0; Fax +49 (0) 3812081 - 202;

http://www.demogr.mpg.de

MPIDR WORKING PAPER WP 2008-009

FEBRUARY 2008

\title{
Reconstruction of continuous series of mortality by cause of death in West Germany for the years 1968-1997
}

Markéta Pechholdová (pechholdova@gmail.com)

This working paper has been approved for release by: Vladimir M. Shkolnikov (shkolnikov@demogr.mpg.de), Head of the Laboratory for Demographic Data.

(C) Copyright is held by the authors.

Working papers of the Max Planck Institute for Demographic Research receive only limited review. Views or opinions expressed in working papers are attributable to the authors and do not necessarily reflect those of the Institute. 
Max Planck Institute for Demographic Research

Laboratory for Demographic Data

Rostock (Germany)

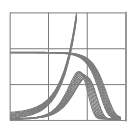

Reconstruction of continuous series of mortality by cause of death in West Germany for the years 1968-1997

\author{
Markéta Pechholdová \\ $\triangle$ pechholdova@gmail.com
}

October 2007 


\section{INTRODUCTION}

A large number of countries use the WHO International classification of diseases and related health problems (ICD) as the main system for coding and tabulating data on causes of death. The classification is periodically updated to reflect progress made in medical knowledge and to incorporate nosologists' suggestions. Every time the new revision is implemented, the time series of mortality by cause of death are interrupted.

Moreover, when making amendments to the classification, national statistical offices rarely produce a double classification (cross-tabulation of deaths by both the actual and the previous revision) that would allow to directly redistribute the deaths of the previous periods according to the new classification. Such an attempt was, for example, made for England and Wales with the transition between ICD8 and ICD9. Nevertheless, the analysis performed by Meslé and Vallin (1993) showed that the transition coefficients derived from the English double classification cannot be applied to other countries, while coding habits change from country to country. To bridge the discontinuities introduced by changes to the classification, it is therefore necessary to take into account such specifities and to reclassify deaths for each country individually.

The main purpose of the present study is to report on the reconstruction of continuous time series of mortality by cause of death in West Germany for the period 1968-1997 covered by the $8^{\text {th }}$ and the $9^{\text {th }}$ ICD revision. The continuous time series have already been reconstructed from data of several countries, namely France (Vallin, Meslé 1988) ${ }^{1}$, Russia (Meslé et al. 1996), Ukraine (Meslé, Vallin 2003), and the Baltic as well as the Causasian countries. ${ }^{2}$ Since recently, work on the Czech Republic has been in progress as well. Continuous time series exist also for the United Kingdom (Office of Population Censuses and Surveys 1983) ${ }^{3}$ and for the Netherlands (Wolleswinkel-van Den Bosch et al. 1996), ${ }^{4}$ although produced via different methodology. The time series resulting from this project will thus enlarge the number of countries where the history of mortality by cause of death can be traced back for several decades and the evolution of population health can be better understood.

ICD not only is a classification system but also provides a large framework of rules and guidelines on mortality and morbidity coding. As these rules play an important role in the process of cause-of-death data collection, they will be described in more detail in the first part of this report, along with a discussion of coding-related and other data quality issues.

The second part then contains a detailed description of the reconstruction process itself, explaining the methodology used, and showing concrete cases. It also gives an overview of specific cause-of-death data related problems, such as the emergence of

\footnotetext{
${ }^{1}$ Along with the main publication, seven annexes were released.

${ }^{2}$ Not published yet.

${ }^{3}$ In the United Kingdom, exceptionally a double codification of deaths was performed on a sample of deaths in 1978, enabling a double classification of deaths by the ICD8 “A-list" and by ICD9 BTL (Basic Tabulation List).

${ }^{4}$ The method used in this study to reclassify the deaths is based on the method performed at INED (Vallin, Meslé 1988), but it was adapted to the needs of the Netherland data. Here, the authors created a nested classification consisting of three levels of refinement for different time periods (from 27 reconstructed causes in 1875-1992 to 92 causes for the 1931-1992 period.)
} 
new diseases, sudden changes in the coding practices, and the persistence of illdefined causes of death.

\section{DATA AND DATA QUALITY}

\subsection{Data collection and coding}

The history of data collection on causes of death in Germany can be traced back to more than 100 years. As in many other countries (e.g. France, Russia), cause-of-death statistics were originally not available on the whole population. From 1877 onwards, the information was first collected in cities with more than 15000 inhabitants. In 1905, a uniform and detailed cause-of-death registration system was introduced. ${ }^{5}$ Up to the 1930s, a specific classification was used in Germany (Statistisches Bundesamt 2005). In 1932, Germany adopted a new classification, already based on the ICD. However, the German classifications differed considerably from the lists proposed by WHO until $1968 .^{6}$ In that year and in order to further improve international comparability, an $8^{\text {th }}$ revision of ICD was adopted by the Federal Statistical Office (Statistisches Bundesamt). Since 1968, West (and East) Germany has been continuously adopting the new ICD revisions. In 1998, ICD 10 was implemented for coding causes of death for the whole of Germany.

The final statistical information about causes of death in West Germany is compiled from two sources. Most of the information for mortality analysis is transmitted from the death certificate filled out by medical doctors, while the complementary demographic data come from vital record registries. The transmission of the two sources of information is slightly different, among other reasons due to the high confidentiality of the medical data. The regulations concerning reporting and transmitting causes of death also differ between the German Länder.

\subsubsection{Collection and transmission of cause-of-death information}

When a death occurs, the corpse is examined by a medical doctor, who confirms the death and reports the following:

a. the time and place of death;

b. the manner of death (natural, non-natural, unknown);

c. the cause of death.

Based on the results of the postmortem examination, the medical doctor releases the death certificate (called differently in various German Länder, either Todesbescheinigung, Leichenschauschein, or Totenschein). The death certificate has two parts, a non-confidential section and a confidential one. The non-confidential section contains the time and place of death, the manner of death, and usually a note on the presence or absence of infectious disease at the moment of death. The confidential part contains information on the cause of death and serves as the basic document for cause-of-death statistics.

\footnotetext{
${ }^{5}$ Thus, the cause-of-death data for West are available as of 1906.

${ }^{6}$ The classification derived from ICD and used for cause-of-death data publication in West Germany prior to 1968 is called DAS (Deutsche Ausführliche Systematik). It provided less detail than does the ICD, but still allowed for international comparison of cause-of-death statistics.
} 


\subsubsection{Regional differences in cause-of-death data collection}

Legislation regarding postmortem examination, filling in death certificate, and the burial and transmission of cause-of-death and related information rests with the federal stats, i.e. each Bundesland. Requirements of postmortem examination and of the content and transmission of death certificate are usually subject to the burial law (Bestattungsgesetz), and the form of death certificate differs between the Länder.

To demonstrate the regional variation in death certificate, suffice it to provide recently used death certificate from North Rhine-Westphalia (Appendix 1), Bavaria (Appendix 2), Hesse (Appendix 3), and Lower Saxony (Appendix 4) as examples.

The death certificates are organized differently. The non-confidential section of all forms contains personal information about the deceased, the time and place of death, and the manner of death. For early-life deaths, the forms distinguish between stillbirth and death at delivery for children whose birth weight exceeded $500 \mathrm{~g}$, with the birth weight often provided in grams. Of the selected examples, the registry offices in North-Rhine-Westphalia and Lower Saxony add information about the burial of the deceased, too, distinguishing between cremation and inhumation. With the exception of Lower Saxony, all of the death certificates presented contain a warning in case infectious disease was diagnosed at the moment of death.

Despite these slight differences, the collected cause-of-death information across the Länder is virtually the same, consisting of the causal chain of pathologies as recommended by WHO and an additional classification for non-natural deaths. In Bavaria, the certifier is provided with an additional sheet to report his findings of evidence of violent death and he can also give a further description of the contributing conditions. Providing such complementary data could potentially increase the resulting data quality, because with more information it later can be easier to select the correct underlying cause of death (Jahn et al. 1992).

As for natural deaths, the transmission of death certificate is nearly the same in all the Länder: the death certificate always passes through the Civil Registry Office (Standesamt). However, if the medical doctor suspects a non-natural origin to the death (suicide, homicide, fall, poisoning etc.) or if the identity of the deceased is unknown, then police investigation is required, making for substantial variation in the transmission of the death certificate in question between the Länder. In Bavaria, the medical doctor passes the certificate to the police, which forwards the filled out document directly to the registry office. In Baden-Württemberg, the doctor waits for the results of the police investigation and only then sends the death certificate to the registry office. In the most populated Land of Germany, North Rhine-Westphalia, the death certificate does not pass through the Civil Registry Office; when the inquiry has been answered, the certificate is sent by the medical doctor directly to the Health Office (Bubenheim 2000). As the final proportions of deaths in North Rhine-Westphalia without a reported cause (ICD9 item $\mathrm{n}^{\circ}$ 799) was remarkably elevated when compared to other regions, it is possible that the Land-specific regulations on death-certificate transmission biases the mortality statistics (Bubenheim 2000).

\subsubsection{Recording demographic information}

Every death in Germany has to be announced to the local Civil Registry Office by a certified person at latest the next working day after the occurrence of death (PersStdG 
$\S 1)^{7}$ The event is then recorded by an officer in the death-records registry (Sterbebuch), with data specified by PersStdG $\S 37$ (Appendix 5). The burial can only take place after registration in this registry.

According to the federal law on population statistics (BevStatG $\S 2$ ), ${ }^{8}$ the civil registry officer enters into the statistical bulletin (Sterbefallzählkarte) the following information about the death:

a. the date of death, the sex, age, marital status, and place of residence;

b. the occupational status of the deceased, legal membership/non-membership in a church, religion, citizenship;

c. the age of the surviving partner (for married persons);

d. the cause of death and duration of life (in hours, if the death occurred within the first 24 hours of life).

The statistical bulletin is then sent on to the Regional Statistical Office (Statistisches Landesamt) at least on a monthly basis (BevStatG § 6).

\subsubsection{Transmission of death certificate and statistical bulletin}

Upon the reception of a filled in death certificate and after having recorded the event in the death records registry, the registry officer sends the confidential part of the death certificate to the Health Office (Gesundheitsamt), where the medical data are exploited for the purposes of the office's tasks (e.g., the surveillance of epidemics) and the death certificate is checked and if necessary, corrected, for completeness and plausibility of the diagnostic information. Afterwards the Health Office transfers the death certificate to the Regional Statistical Office.

At the Regional Statistical Office, the causes of death, written by hand into the death certificate, are coded in the terms of the current ICD revision. ${ }^{9}$ The majority of German coders are medical amateurs (Giersiepen et al. 1989) who receive regular professional training on coding rules and changes in the coding instructions. The training is organized centrally (to assure data comparability between the Länder) and since recently has been organized by the Federal Statistical Office in cooperation with the DIMDI (Deutsche Institut für Medizinische Dokumentation und Information) on a yearly basis. Training materials can be found at www.dimdi.de.

After the coding, the two sources of mortality information (the statistical bulletin and the death certificate) are combined, based on the death record registry number (Sterbebuchnummer). The confidential death certificate is then returned to the Health Office, where it is archived for several years, depending on the Bundesland.

Figure 1 represents the scheme of the current system of collection and the treatment of data on mortality and cause of death in Germany.

\footnotetext{
${ }^{7}$ Personenstandsgesetz

${ }^{8}$ Gesetz über die Statistik der Bevölkerungsbewegung und die Fortschreibung des Bevölkerungsstandes, from $4^{\text {th }}$ June 1957

${ }^{9}$ An exception to this model is Hamburg, where the causes of death are coded at the health office.
} 


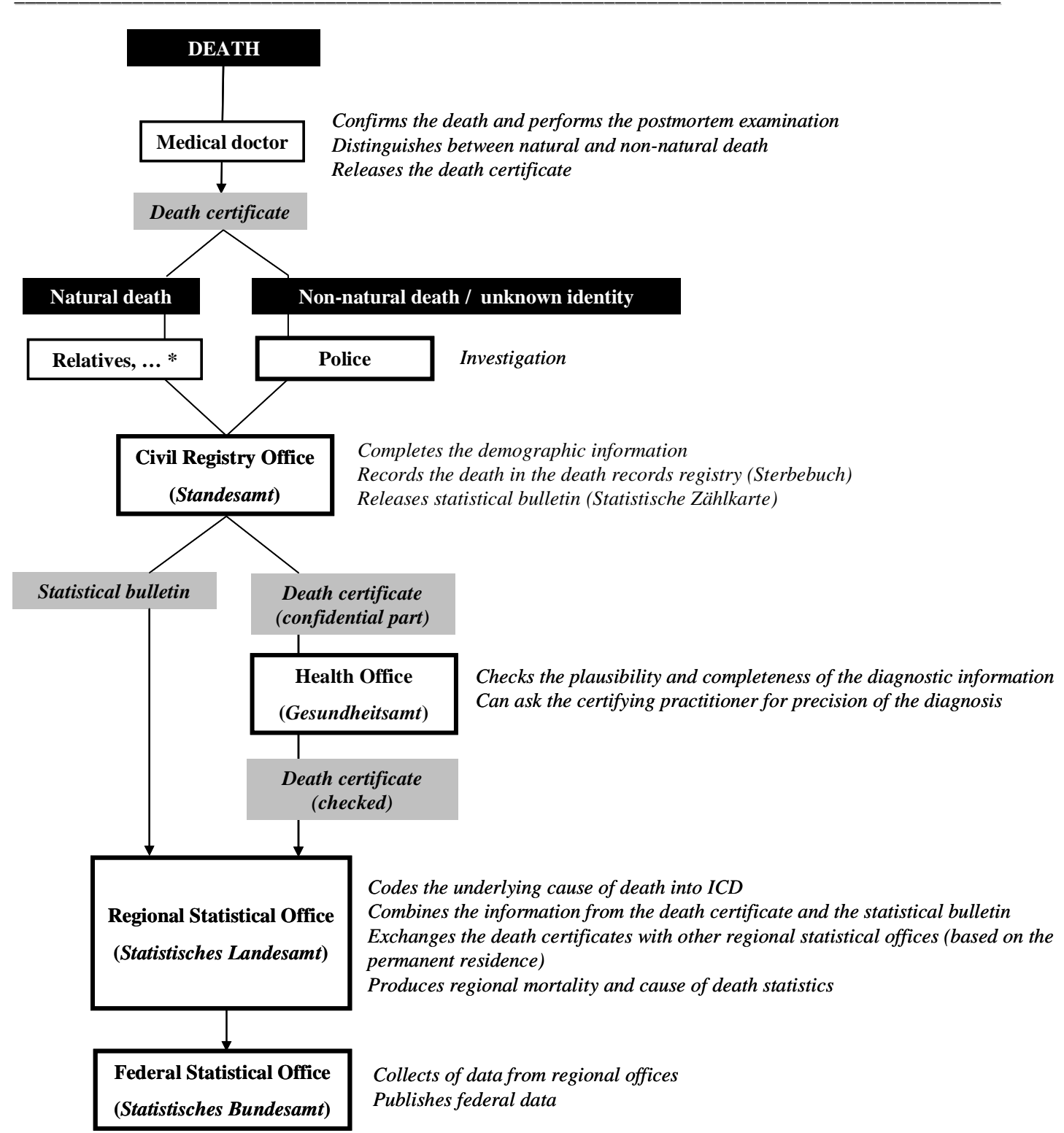

Figure 1 Schematic representation of the current system of the collection and treatment of data on mortality and cause of death in Germany ${ }^{10}$

* If the death occurred in an institution, the statistical bulletin is filled in by the institution and then sent directly to the regional statistical office (Bubenheim 2000).

Mortality statistics in Germany are based on the place of residence of the deceased. Therefore, before further processing, the certificates of deaths that occurred outside the residence region are exchanged between the Regional Statistical Offices (Bubenheim 2000). The latter then computerize the data and prepare statistics on regional mortality and cause of death. The country data, which we are using in the present study, are summarized from the regional tables.

\footnotetext{
${ }^{10}$ Note: The scheme illustrated shows only one of the various ways of transmission possible: This scheme is used in Bavaria. There are substantial regional differences as to non-natural death and the death of a person unknown (described in Section 2.1.2)
} 


\subsection{Causes of death: rules on reporting and coding}

As mentioned, legislation concerning death certification varies by Bundesland. However, WHO recommendations on describing the chain of pathologies leading to death are strictly followed in all of the German Länder (Statistisches Bundesamt 2005). Since 1967, WHO has been recommending to report "all those diseases, morbid conditions or injuries which either resulted in or contributed to death and the circumstances of the accident or violence which produced any such injuries" so as to assure that it is only the relevant conditions that are reported on the death certificate.

Figure 2 shows the international death certificate as recommended by WHO. The first part of the certificate (I) describes the train of conditions and events directly leading to death, with the underlying condition on the last line. The second part (II) of the certificate provides additional information on diseases diagnosed at the moment of death; these diseases are not believed to have contributed directly to the fatal outcome.

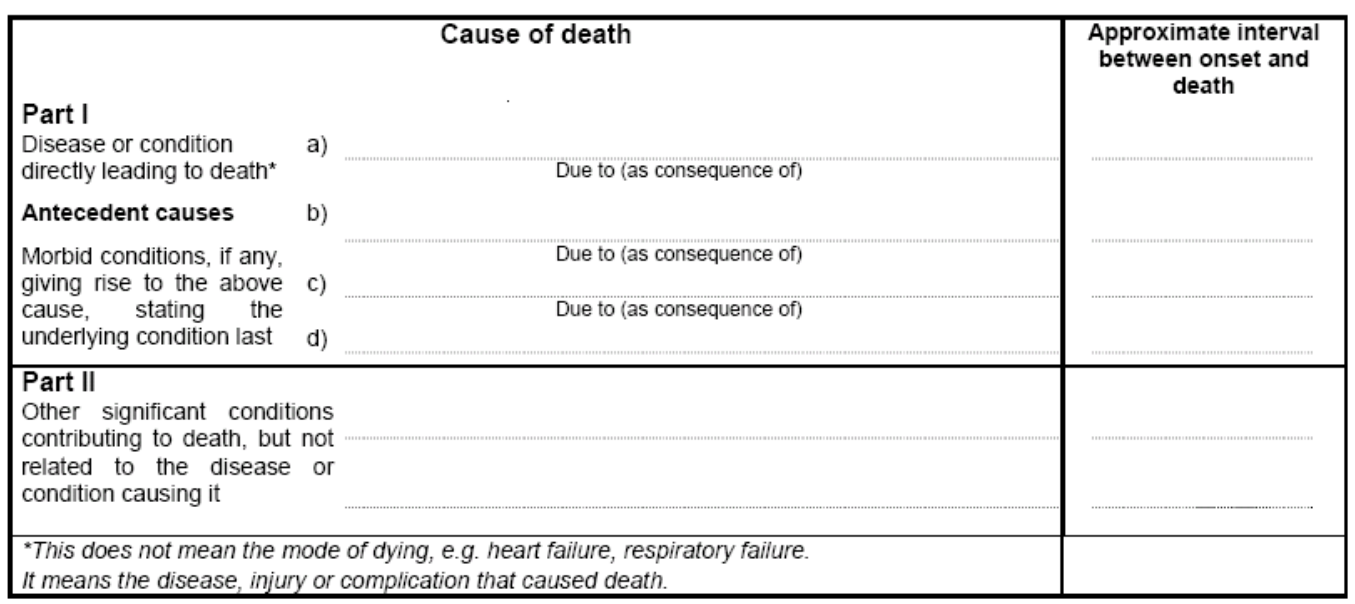

Figure 2 International form of medical death certificate

Source: ISTAT 2003

In all Länder, the death certificate contains information about the immediate (direct) (a), the intervening (b, c) and the underlying (main, initial) (d) cause of death (Grundleiden) as well as a list of associated significant conditions (Epikrise), based on the international form of the medical death certificate.

The certificate should also contain a note about the time elapsed between the onset of the disease and death. This helps the certifying practitioner to establish the correct sequence of conditions and helps the coder to choose the proper underlying cause. ${ }^{11}$

Up to the present, only the underlying cause of death has been processed in West Germany. It is defined by WHO as "the disease or injury that initiated the train of

11 If information about the duration of the disease and the death is not known, then the certifying practitioner should make a sensible evaluation of it. 
events leading directly to death, or the circumstances of the accident or violence that produced the fatal injury", selected by the Sixth Decennial International Revision Conference in 1948 as the cause of death for primary tabulation. The idea was to suit ICD data to the purposes of public health, where the curing of the originating disease is the most effective way to lower the mortality.

Beyond the analysis of the underlying cause, the diversity of information given on the death certificate helps to estimate the impact of significant contributing factors, such as hypertension, asthma or diabetes, that are frequently present at the time of death, but that are usually not lethal by themselves. It is likely that in the future multiple causes of death, i.e. all diseases or conditions reported on the death certificate, will be coded and processed in the German statistical offices. The implementation of an automated coding system is also under consideration (Statistisches Bundesamt 2005).

The structure of the international death certificate is meant to facilitate the selection of the primary cause of death among other diseases. In the easiest case, the chain of diseases leading to death contains only one item and the selection of the underlying cause of death is then simple and clear. If more than one disease is listed in the certificate, the coding rules play a decisive role. A properly completed cause-of-death section of the death certificate provides an etiologic explanation of the order, type, and association of events resulting in death. However, the death certificate is often filled in incompletely or incorrectly, so the coders are left with the task of determining the underlying cause of death. The coding rules have been evolving along with the revisions of the ICD. These rules have been growing more and more precise and complex. The timing of the change in the coding rules might differ considerably between individual countries (Meslé 1995). Nevertheless, as the current rules are still based on the principles valid since the $6^{\text {th }}$ revision of ICD, certain continuity should be assured.

Figure 3 illustrates how the selection of the underlying cause of death works in practice. There is one General Principle and there are three subsidiary Selection Rules. The third selection rule works as a filter for the previous selections. Finally, there are several Modification Rules (A-F). When more than one cause is reported on the death certificate, the task is to determine the underlying cause by applying the General Principle or Rules 1-3. Modification Rules then deal with special epidemiological circumstances where other conditions are more relevant for tabulation than are the condition selected by General Principle or Selection Rules.

Rule 3 is subject to numerous precisions and therefore is a possible source of important statistical discontinuities. Spectacular is the example of Great Britain. Until 1983, Rule 3 was not applied strictly, leading to an artificial increase in mortality from immediate causes of death reported on the first part of the death certificate, and the major underlying disease reported in the second part was ignored. In 1984, new coding instructions applied and mortality from pneumonia and influenza dropped immediately to less than half of its value in 1983 (Meslé 1995). 


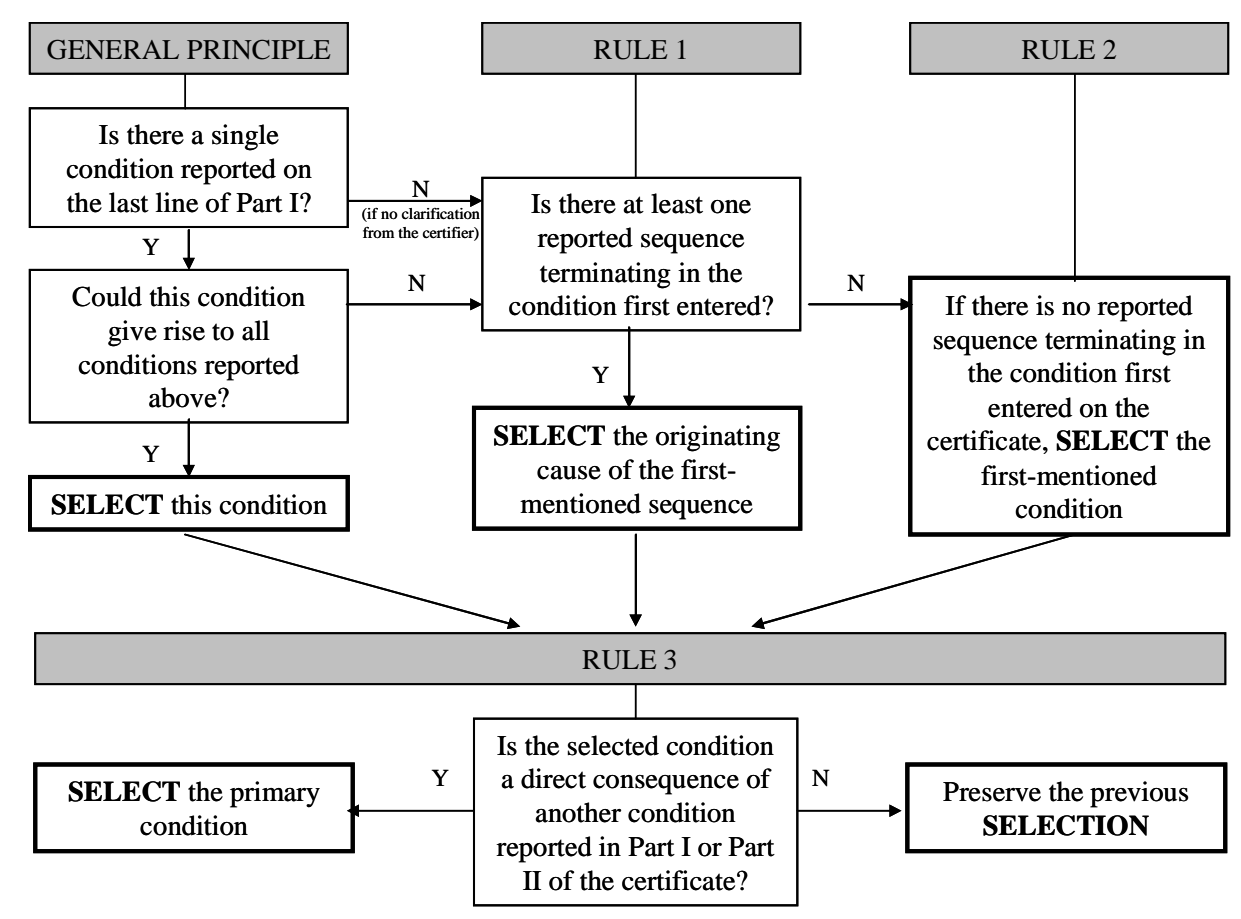

Figure 3 Schematic representation of the underlying cause of death selection algorithm

\subsection{Description of the data collected}

The data for the reconstruction project, provided by the Federal Statistical Office, are extracted from two types of sources: for the 1968-1979 period, they were computerised from the printed statistics on cause of death, while as of 1980 the data has been provided in electronic format. The collected data are incoherent with respect to the age scale, the level of classification detail, the classification of causes of death, and possibly other hardly traceable inconsistencies in the quality of cause-of-death registration. Table 1 provides a summary on the data collected by the MPIDR for the purpose of reconstructing continuous time-series of mortality by cause of death in West Germany.

Table 1 Summary information on cause-of-death data available for the reconstruction of continuous time-series of mortality by cause of death in West Germany (1968-1997)

\begin{tabular}{|c|c|c|c|c|c|c|}
\hline Period & Classification & $\begin{array}{c}\text { Number of } \\
\text { items }\end{array}$ & List & Age group format & $\begin{array}{l}\text { Territorial } \\
\text { coverage }\end{array}$ & Source \\
\hline 1968 & ICD8 & $\begin{array}{c}111 \\
337 \\
10 \\
\end{array}$ & \begin{tabular}{|c|} 
Groups of 3-digit and 4 \\
digit items \\
3-digit items \\
4-digit items \\
\end{tabular} & $\begin{array}{c}0-23 \text { hrs, } 24 \text { hrs }-6 \text { days, } 7-27 \text { days, } \\
28 \text { days- } 1 \text { year, } 1-4,5-9,10-14, \ldots, \\
85-89,90+\text {, unknown (incl. } \\
\text { distinction of deaths in/outside of }\end{array}$ & West Germany & $\begin{array}{c}\text { Federal Statistical } \\
\text { Office Wiesbaden } \\
\text { (printed data) }\end{array}$ \\
\hline 1969-1978 & ICD8 & $\begin{array}{l}111 \\
337 \\
157\end{array}$ & \begin{tabular}{|c|} 
Groups of 3-digit and 4 \\
digit items \\
3-digit items \\
4-digit items \\
\end{tabular} & $\begin{array}{c}0-23 \text { hrs, } 24 \text { hrs }-6 \text { days, } 7-27 \text { days, } \\
28 \text { days- } 1 \text { year, } 1-4,5-9,10-14, \ldots \text {, } \\
85-89,90+\text {, unknown (incl. } \\
\text { distinction of deaths in/outside of }\end{array}$ & dtto & dtto \\
\hline 1979 & ICD9 & $\begin{array}{l}104 \\
299 \\
130\end{array}$ & $\begin{array}{c}\text { Groups of 3-digit and 4 } \\
\text { digit items } \\
\text { 3-digit items } \\
\text { 4-digit items }\end{array}$ & $\begin{array}{c}0-23 \text { hrs, } 24 \text { hrs }-6 \text { days, } 7-27 \text { days, } \\
28 \text { days- } 1 \text { year, } 1-4,5-9,10-14, \ldots, \\
85-89,90+\text {, unknown (incl. } \\
\text { distinction of deaths in/outside of }\end{array}$ & dtto & dtto \\
\hline 1980-1997 & ICD 9 & 892 & 3-digit items & $\begin{array}{c}0,1-4,5-9,10-14, \ldots, 85-89,90+, \\
\text { unknown }\end{array}$ & dtto & $\begin{array}{c}\text { Federal Statistical } \\
\text { Office Wiesbaden } \\
\text { (electronic data) }\end{array}$ \\
\hline
\end{tabular}


Note: We do not work with the N-classification of external causes of death (i.e. by nature of the injury), therefore the table includes only to the natural causes of death and the E-classification (of environmental events, circumstances, and conditions as causes of injury, poisoning, and other adverse effects).

The time period between 1968 and 1978 is covered by ICD8. The data on the causes of death are presented in the form of a short list consisting of a mixture of single 3digit items, 4-digit items selected, and of the groups of either 3-digit or 4-digit items, or both. The mixed groups are not formed by published 3- or 4-digit items, but the published 4-digit positions usually give the detail for a tabulated 3-digit item. Additionally, there is a substantial difference between the given detail in the first year and the following years of the ICD8, while the number of the tabulated 4-digit codes increased from 10 in 1968 to 157 in 1969 . In order to obtain the same level of detail for 1968 as for the other years, the deaths from the 1968 items without sufficient detail were redistributed according to the proportions observed in 1969 and 1970. In 1971, the classification was modified by adding ICD8 item $\mathrm{n}^{\circ} 7784$ Debility when having a birth-weight of at least 2500 grams. This position is not mentioned in the English manual for the $8^{\text {th }}$ revision of the ICD, therefore it is possible that it has been applied in Germany only. The published age scale provides large details on the first year of life (first day, early, neonatal, and post neonatal deaths), while for older age the data are tabulated by 5-year age groups up to the open age interval 90 years and above. Additionally, the proportion of deaths occurring in institutions (Davon in Anstalten column) is given.

The $9^{\text {th }}$ revision of the ICD was introduced to German cause-of-death statistics in 1979. The structure and detail of the data available in the printed version in 1979 is very similar to the one of ICD8, i.e. it has a mixture of single 3-digit codes, 4-digit codes, and groups of codes presented with the same age group format as in the previous years. A large amendment was introduced in 1980, when the federal statistical office started to tabulate the full 3-digit ICD9 list in electronic format. As for the first year of ICD8, we redistributed the deaths of 1979, classified in groups, proportionally to the 3-digit level structure observed in 1980 and 1981 so as to overcome the differences in the published detail in the frame of the same classification. In the electronic tabulation system, the first year of life no longer is divided into sub periods, there are thus 20 age groups $(0,1-4,5-9,10-14, \ldots, 85-89$, $90+$, unknown). This age structure was used for the reconstruction of the continuous time-series.

In many countries, the published ICD lists slightly differ from the official version. It is a common practice not to publish items with zero mortality for a given year. In Germany, the following ICD9 items were not used during the whole ICD9 period for coding purposes:

020 Plague

024 Glanders

026 Rat-bite fever

092 Early syphilis, latent

196 Secondary and unspecified malignant neoplasm of lymph nodes

197 Secondary malignant neoplasm of respiratory and digestive systems

198 Secondary malignant neoplasm of other specified sites 


\author{
$321 *$ Meningitis due to other organisms \\ 484* Pneumonia in infectious diseases classified elsewhere \\ $517 *$ Lung involvement in conditions classified elsewhere \\ 631 Other abnormal product of conception \\ 638 Failed attempted abortion \\ 645 Prolonged pregnancy \\ 650 Normal delivery \\ 662 Long labour \\ 675 Infections of the breast and nipple associated with childbirth \\ 676 Other disorders of the breast associated with childbirth and disorders of lactation \\ 713* Arthropathy associated with other disorders classified elsewhere
}

The items with an asterisk belong to the dual coding system introduced in ICD9 (so called "dagger and asterisk system", where two codes contain information about the underlying disease [dagger] as well as a manifestation in a particular organ or site, a clinical problem per se [asterisk]). If dual coding is not used, the dagger code is given preference. Interestingly, items $\mathrm{n}^{\circ} 196-198$ (referring to secondary malignant neoplasms) were not used in the West German adaptation of ICD9.

\title{
2.4 Data quality
}

Reporting, transmitting, and coding the cause of death is problematic in all of the countries and directly affects the quality and comparability of the resulting data (Meslé et al. 1996). Imprecision can be introduced at any of those steps.

\subsubsection{Cause of death certification}

Postmortem examination is a key factor in cause-of-death statistics. Several issues of unreliability have been reported in Germany with respect to postmortem examination and documentation, originating primarily from the absence of uniform federal regulations, vague definitions of natural and violent death, missing routine in postmortem examination (?) or from the low financial rating of this "last service to the patient". Often, there is a certain pressure from the police or relatives to certify a natural death rather than a non-natural or violent one (Madea et al. 2003).

The reliability of medical certification based on postmortem examination was compared to autopsy results in a "Görlitz study" (Modelmog et al. 1992). The study was performed in the former East Germany in 1987, that is not the country of our interest, but the results probably point at some common issues of postmortem examination based cause-of-death certification. Autopsy was performed on virtually all deaths that occurred during a particular year in the city of Görlitz (a total of 1023 deaths). In approximately $30 \%$ of the cases, the diagnosis on the death certificate differed from the autopsy results on the level of the ICD9 main chapter. The highest agreement was reported for malignant neoplasms (89\%), while circulatory disease was confirmed only in $69 \%$ of the cases. The autopsy study also revealed an underestimation of cancer mortality by $11 \%$ and an overestimation of cardiovascular 
diseases by $20 \%$. On the one hand, this finding supports the hypothesis that cancer mortality is generally underreported due to underdetection, which is believed by some authors to be between 20 and 30\% (Becker et al. 1998). On the other hand, the presence of cancer at the moment of autopsy does not necessarily mean that the cancer finally caused the death of the patient in question.

After the autopsy, $64 \%$ of the previously ill-defined causes of death were attributed to cardiovascular conditions and the rest was distributed to external, respiratory, tumorous, and infectious diseases, no more deaths thus remained assigned to ill-defined conditions.

A physician's awareness of the existence of mortality statistics as well influences the reliability of the cause-of-death certification. A study conducted in Germany revealed that $25 \%$ of the physicians surveyed did not know that cause-of-death statistics existed and another $30 \%$ of physicians were unaware that every death certificate is included in these statistics (Müller et al. 1990). Another study (Jahn et al. 1995) found that death certificate was incorrectly filled in by emergency medical doctors more so than by clinical specialists and that cardiovascular diseases was the most affected group.

\subsubsection{Coding}

The selection of the underlying cause of death, based on the diverse information provided on the death certificate, is to some extent subjective, while this selection partially depends on the coder's experience, the degree of his medical awareness, and the local coding instructions. In West Germany, several studies were conducted to assess the reliability of information on underlying causes of death. In a major study (Jahn et al. 1995), 4313 death certificates from three different regions (Bremen, Hesse, Lower Saxony) were examined in order to find out 1) if the quality of causeof-death data can be improved by reinforcing the systematic certificate checks at the health offices and 2) if automated coding could eliminate some of the regional differences in the reported mortality structure by cause of death. The experiment included death certificates incompletely filled in, death certificates with a mention of malignant neoplasm as underlying cause, and a random selection of remaining death certificates. In $77 \%$ of the cases, the death certificate required further specification from the certifying doctor and in $90 \%$ the clarification was finally obtained.

Based on the completed information, new death certificate (so called "Project Death Certificates") was issued. The main evaluating strategy was to match and compare the coding of the underlying cause of death from the original and the project death certificate.

During the automated recoding (ACME) ${ }^{12}$ of the underlying cause based on complete information on the project death certificate, $12 \%$ of the coding decisions were changed on the level of the main ICD9 groups compared to the automated coding of the original death certificate. While in the group of cardiovascular diseases the change corresponded to an average value of $12 \%$, in the group of malignant neoplasms the underlying cause was changed to/from another main group of causes only in $1.8 \%$ of

\footnotetext{
${ }^{12}$ ACME (Automated Classification of Medical Entities) - a computer program used by the National Center for Health Statistics (NCHS) to select the underlying cause of death after the individual diagnoses have been coded
} 
the cases. In case of respiratory diseases, the diagnosis was changed to nonrespiratory disease in $25 \%$ of the death certificates. The remaining groups of causes yielded inconsistent results, with higher proportions of imprecision. Regarding cancer mortality, in $1-2 \%$ of cases the presence of tumour was retrieved by complementary inquiry while there was no mention of cancer in the original death certificate. However, there is an overreporting of mortality from cardiovascular disease by 3-7\%. A more detailed analysis has shown that this effect is not uniform within the cardiovascular group: While an underestimation was found for ischemic heart disease (ICD9 items $\mathrm{n}^{\circ} 410-414$ ) and for cerebrovascular diseases (ICD9 items $\mathrm{n}^{\circ} 430-438$ ), the remainder of the cardiovascular conditions was strongly overreported.

To assess the impact of manual coding on data reliability, the project death certificates were recoded during the 1993-1994 period by three coders from three different Länder. The resulting inter-observer differences in coding causes of death were found to be a relevant source of data bias. On the level of 3-digit ICD9 items, a 65\% interobserver agreement was found ( 3 coders agreed on the selection of the underlying cause of death), on the level of the 4-digit code the inter-observer agreement decreased to $59 \%$.

Very similar results were yielded by an earlier study, where seven coders from six different Länder recoded 1136 death certificates from Bremen from 1985. The design of this experiment was different in that it mainly focused on cardiovascular deaths and the age range has been reduced to 25-69 years. But similarly, a $68 \%$ inter-observer agreement on a 3-digit level and a 61,5\% agreement on a 4-digit level was reported (Giersiepen et al. 1989). An analogous structure to the cause of data imprecision (i.e. an underestimation of cancer and overestimation of cardiovascular diseases) was found in other countries, e.g., in Russia (Meslé et al. 1996).

Table 2 Inter-observer agreement by the main ICD9 chapters

\begin{tabular}{|c|c|c|}
\hline 1. Definitions & Jahn et al. 1995 & Giersiepen et al. 1989 \\
\hline Year & 1993-1994 & 1985 \\
\hline Territory & $\begin{array}{l}\text { Bremen, Gifhorn, } \\
\text { Marburg-Biedenkopf, } \\
\text { Fulda }\end{array}$ & Bremen \\
\hline Sample size (N of death certificates) & 3281 & 1136 \\
\hline Method & $\begin{array}{l}\text { Parallel coding of } \\
\text { completed death } \\
\text { certificates classified } \\
\text { previously as incomplete, } \\
\text { containing the mention of } \\
\text { malignant neoplasm plus a } \\
\text { random selection of } \\
\text { certificates }\end{array}$ & $\begin{array}{l}\text { Parallel coding of death } \\
\text { certificate, all cardiovascular } \\
\text { deaths in } 1 \text { year plus } 50 \% \\
\text { sample of the remaining } \\
\text { deaths in age group } 25-69\end{array}$ \\
\hline Definition of agreement & $\begin{array}{l}\text { All } 3 \text { of the } 3 \text { coders agree } \\
\text { on the selection of the } \\
\text { underlying cause of death } \\
\text { on the level of the ICD9 } \\
\text { chapters (\%) }\end{array}$ & $\begin{array}{l}\text { At least } 3 \text { out of } 7 \text { coders } \\
\text { from } 6 \text { Länder agree on the } \\
\text { selection of the underlying } \\
\text { cause of death on the level of } \\
\text { the ICD9 chapters }(\%)\end{array}$ \\
\hline 2. Results & \multicolumn{2}{|c|}{ Agreement (\%) } \\
\hline
\end{tabular}




\begin{tabular}{|c|c|c|}
\hline $\begin{array}{l}\text { I Infectious and parasitic diseases } \\
(000-139)\end{array}$ & 50 & 19 \\
\hline $\begin{array}{l}\text { II Neoplasms } \\
(140-239)\end{array}$ & 94 & 84 \\
\hline $\begin{array}{l}\text { III Endocrine, nutritional, and metabolic diseases } \\
(240-279)\end{array}$ & 45 & 29 \\
\hline $\begin{array}{l}\text { IV Diseases of the blood and blood forming organs } \\
(280-289)\end{array}$ & 58 & - \\
\hline $\begin{array}{l}\text { V Mental disorders } \\
(290-319)\end{array}$ & 27 & 47 \\
\hline $\begin{array}{l}\text { VI Diseases of the nervous system and sense organs } \\
(320-389)\end{array}$ & 40 & 37 \\
\hline $\begin{array}{l}\text { VII Diseases of the circulatory system } \\
(390-459)\end{array}$ & 81 & 59 \\
\hline $\begin{array}{l}\text { Ischemic heart disease } \\
410-414\end{array}$ & 61 & 83 \\
\hline $\begin{array}{l}\text { Cerebrovascular diseases } \\
\text { (430-438) }\end{array}$ & 71 & 66 \\
\hline $\begin{array}{l}\text { VIII Diseases of the respiratory system } \\
(460-519)\end{array}$ & 61 & 28 \\
\hline $\begin{array}{l}\text { IX Diseases of the digestive system } \\
(520-579)\end{array}$ & 66 & 56 \\
\hline $\begin{array}{l}\text { X Diseases of the genitourinary system } \\
(580-629)\end{array}$ & 33 & 24 \\
\hline $\begin{array}{l}\text { XI Complications of pregnancy, childhood, and the } \\
\text { puerperium } \\
(630-676)\end{array}$ & - & - \\
\hline $\begin{array}{l}\text { XII Diseases of the skin and subcutaneous tissue } \\
(680-709)\end{array}$ & 0 & - \\
\hline $\begin{array}{l}\text { XIII Diseases of the musculoskeletal system and } \\
\text { connective tissue } \\
(710-739)\end{array}$ & 35 & - \\
\hline $\begin{array}{l}\text { XIV Congenital anomalies } \\
(740-759)\end{array}$ & 47 & - \\
\hline $\begin{array}{l}\text { XV Certain conditions originating in the perinatal } \\
\text { period } \\
(760-779)\end{array}$ & 83 & - \\
\hline $\begin{array}{l}\text { XVI Symptoms, signs, and ill-defined conditions } \\
(780-799)\end{array}$ & 68 & 26 \\
\hline $\begin{array}{l}\text { XVII Injury and poisoning } \\
(800-999)\end{array}$ & 73 & 52 \\
\hline
\end{tabular}

Source: Jahn et al. 1995, Giersiepen et al. 1989 
These results to a certain extent quantify the impact of the coders' decision on the quality of the tabulated data. In other words, in approximately one third of the cases the selection of the primary cause of death was uncertain in both studies. Nevertheless, when only the large ICD9 chapters were taken under consideration, the agreement increased up to $87 \%$ in both studies. Table 2 shows the rates of inter-observer agreement by groups of cause of death in both studies. With the exception of ischemic heart disease and mental disorders, the inter-observer agreement rates are higher for the later study (Jahn et al. 1995). Two simultaneously valid explanations are possible: Firstly, the coding in the later study was compared using the (project) death certificate corrected, which helped to clarify the selection of the underlying cause of death and confirmed the positive effect of the amount of medical information on the coding quality. Secondly, it may be the effect of the continuous effort made for the improvement of cross-regional comparability of the coding practices across West Germany.

\subsubsection{Unknown and ill-defined causes of death}

The data quality can also be assessed indirectly from the structure of the reported causes. For various reasons, some portion of the deaths remains without specific diagnosis. The ICD provides specific categories for these cases - the whole ICD9 Chapter XVI refers to "symptoms, signs, abnormal results of laboratory or other investigative procedures, and ill-defined conditions regarding which no diagnosis classifiable elsewhere is recorded". Moreover, within each ICD chapter there is a category for ill-defined conditions within the framework of the given group of diseases. The percentage of ill-defined causes provides a proxy measure of the data quality and points at specific diagnostic or coding-related problems.

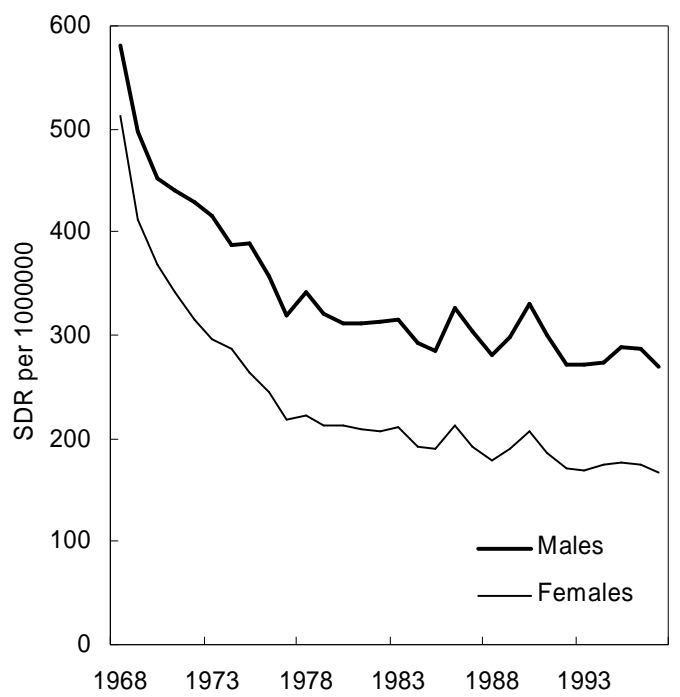

Figure 4 Age-standardized death rate for ICD9 Chapter XVI: Symptoms, signs, and ill-defined conditions (items $\mathbf{n}^{\circ} \mathbf{7 8 0 - 7 9 9 )}$

Between 1968-1997 the proportion of ill-defined causes (ICD9 items $\mathrm{n}^{\circ} 780-799$ ) in West Germany dropped from $3.0 \%$ to $2.8 \%$ for males and from 4.2 to $2.9 \%$ for females. This decrease was not regular, however: Overall mortality from ill-defined 
causes declined steeply during ICD8, followed by a much more moderate decrease up to the present (Figure 4). ${ }^{13}$

Of Chapter XVI, the last three ICD9 items deserve special attention: item $\mathrm{n}^{\circ} 797$, Senility, item $n^{\circ} 798$, Sudden death from unknown cause, and item $n^{\circ} 799$, Other ill-defined and unknown causes of morbidity and mortality. The age-standardized death rates from these categories are shown in Figure 5. The breakdown by individual ICD9 items reveals that the main improvement in the completeness of the cause-of-death data was due to a rapid decrease of reporting senility as the underlying cause of death in the elderly. The mortality from ICD9 item $n^{\circ} 798$ has declined only since the late 1980s. However, an increasing trend in the last category (ICD9 item ${ }^{\circ}$ 799) suggests that there is a persisting problem in reporting or transmitting cause-ofdeath data.
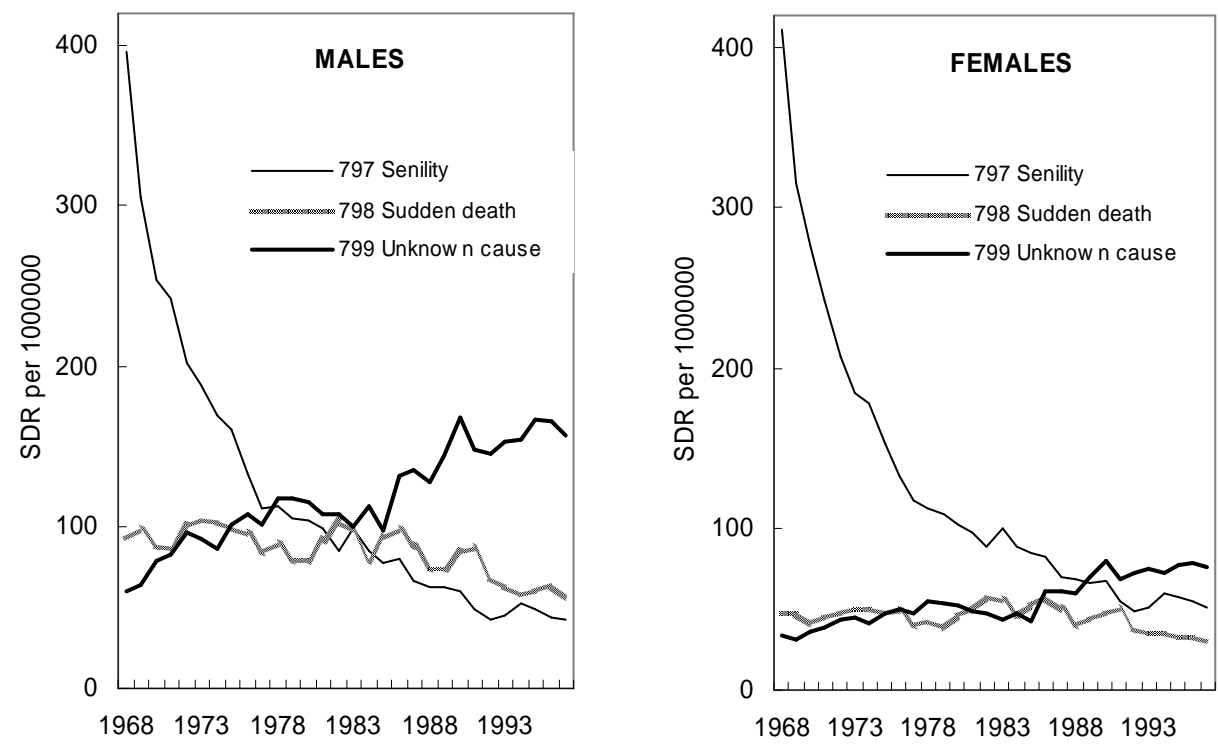

Figure 5 Age-standardized death rate per 1000000 for the three most common ill-defined causes of death: item $n^{\circ} 797$ (senility), item $n^{\circ} 798$ (sudden death) and item $n^{\circ} 799$ (unknown cause).

In the case of senility, the major improvement took place at the most advanced age. Between 1968 and 1997 the proportion of deaths attributed to senility decreased from nearly $20 \%$ to less than $5 \%$ for the oldest age group (90 years and older), which is a great improvement in the cause of death diagnostics and reporting. A remarkable decrease was observed in the younger old age as well. The percentages are generally higher for females than they are for males (Figure 6).

\footnotetext{
${ }^{13}$ Note: The data for this section are taken from the reconstructed time series presented later in this study.
} 

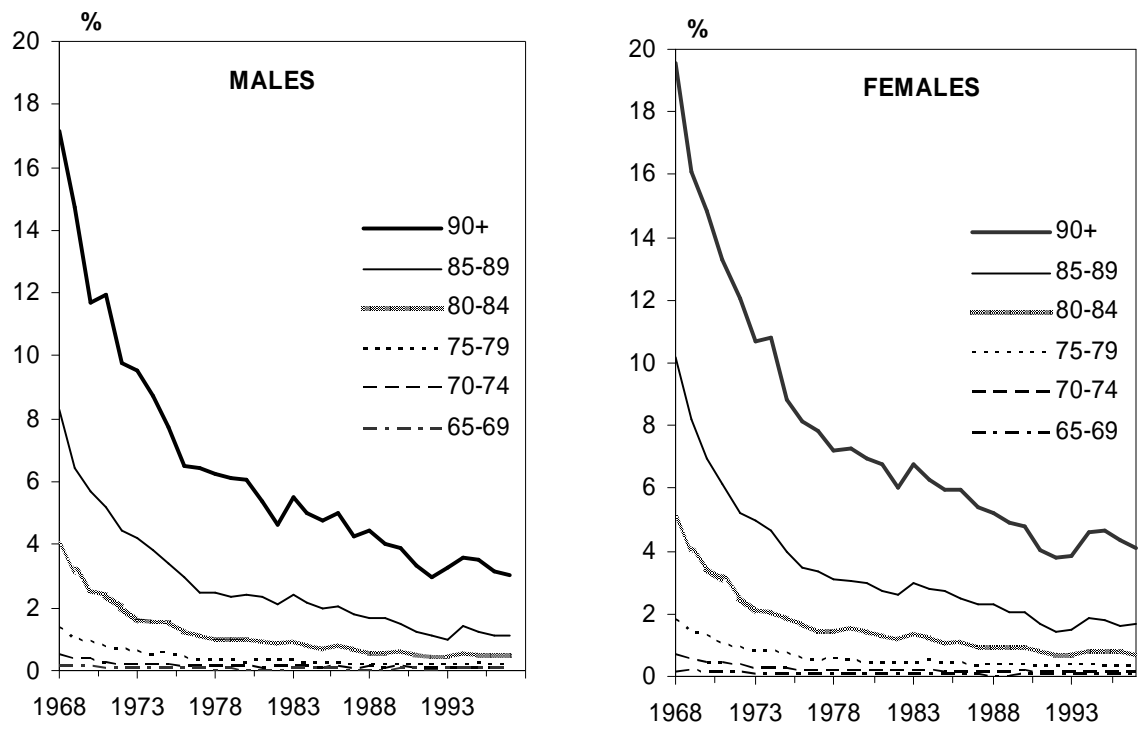

Figure 6 Proportions (\%) of deaths classified under Senility (item $n^{\circ} 797$ ) by age, 65 years, and beyond

Mortality from sudden death, measured by age-standardized death rate (Figure 5), recently has been declining after decades of stagnation. Sudden death from unknown cause is typical of an outstanding polarity between age 0 and the reminder of the age scale: The proportions of this cause of death are relatively low, rarely surpassing $1 \%$ for age groups 5-9 to $90+$, while the situation is of a very different character for the early stages of life. As the trend in "cot death"14 is not sufficiently captured in Figure 7, the latter which shows different proportions of sudden deaths among all deaths by age, they are represented in Figure 8. The mortality level had an upward tendency in the 1980s and this suggests a gradual shift in the coding or the certifying practices within the framework of ICD9. From the early 1980s, mortality from sudden infant death from unknown cause steeply rose until 1991, when it reached $26 \%$ for males and $23 \%$ for females compared to overall infant mortality. ${ }^{15}$ From 1991 onwards, mortality from the sudden death syndrome steeply declined. Similar tendencies were observed in other countries, e.g. France, possibly attributed to "reduce the risk" campaigns that held there (Barbieri 1998). The recognized risk factors for cot death include maternal smoking, non-breast feeding, covering the full body with blankets during sleep, and proneness to a particular sleeping position (sleeping on the belly). In Germany (as in many other countries) a campaign against the prone position was launched in 1992. It had an instant positive effect on sudden infant mortality (Schellscheidt et al. 1997). Unlike for the rest of Chapter XVI, sudden infant death thus represents a specific cause of death whose aetiology and ways of prevention are subject of vast current research.

\footnotetext{
14 "Cot death" is a term commonly used to describe sudden and unexpected infant death that is initially unexplained. The equivalent medical term is "sudden unexpected death in infancy" (SUDI). A thorough postmortem examination in part provides an explanation for the sudden death. The deaths that remain unexplained still are usually registered as sudden infant death syndrome (SIDS).

${ }^{15}$ This alarming trend is not captured in the age-standardized death rate, because general infant mortality (both sexes) declined from $22.7 \%$ o to $4.9 \%$ and its weight on the SDR thus decreased.
} 

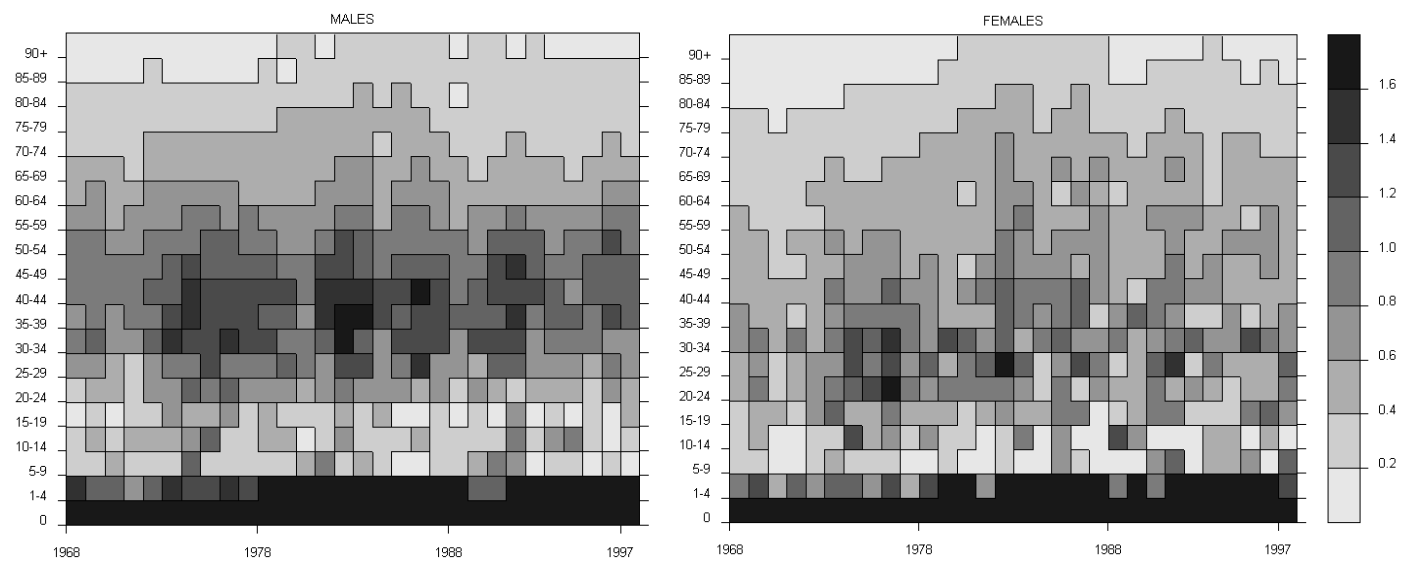

Figure 7 Lexis map of the proportions (\%) of ICD9 item $n^{\circ} 798$, Sudden death, cause unknown, from the total of deaths by age and year, 1968-1997 ${ }^{16}$

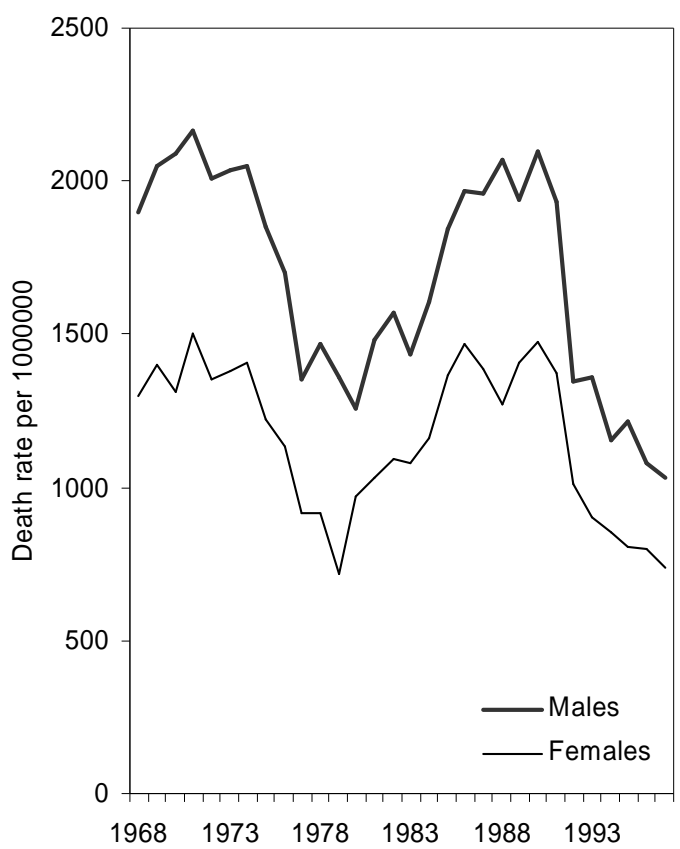

Figure 8 Death rates from ICD9 item $n^{\circ}$ 798, Sudden death, cause unknown, at age 0, 1968-1997

The third category (ICD9 item $\mathrm{n}^{\circ}$ 799) accounts for the remaining deaths by unknown cause. Mortality from unknown causes is rising, especially for males (Figure 9). Bubenheim (2000) investigated the background of item $n^{\circ} 799$ in West Germany around year 1980. He suggests that the content of this item is not independent of the cause of death, i.e. is not random. He assumes that the information on cause of death

\footnotetext{
${ }^{16}$ To construct these figures, we use the Lexis program written by K. Andreev, (Andreev 1999)
} 
is missing when a death poses a forensic problem due to regional differences in death certificate transmission. The percentage of unknown causes was extremely high in North Rhine-Westphalia compared to other three Länder in question (Bavaria, Baden-Württemberg and Berlin, while the death certificate was nearly the same. The main difference was the transmission of death certificate in case of non-natural death. Our analysis of the age structure of deaths confirmed that around 1980 the diagnosis was missing primarily for deaths occurring in the mid-productive age for both sexes (age group 25-44). However, compared to 1980, the proportions of deaths assigned to ICD9 item $\mathrm{n}^{\circ} 799$ has been increasing and substantially expanding to the whole productive age (15-65) up to the present (Figure 9). With the data aggregated to the federal level and to 3-digit items, we are not able to detect regions or specific diagnostic or legal problems behind these unfavourable trends.
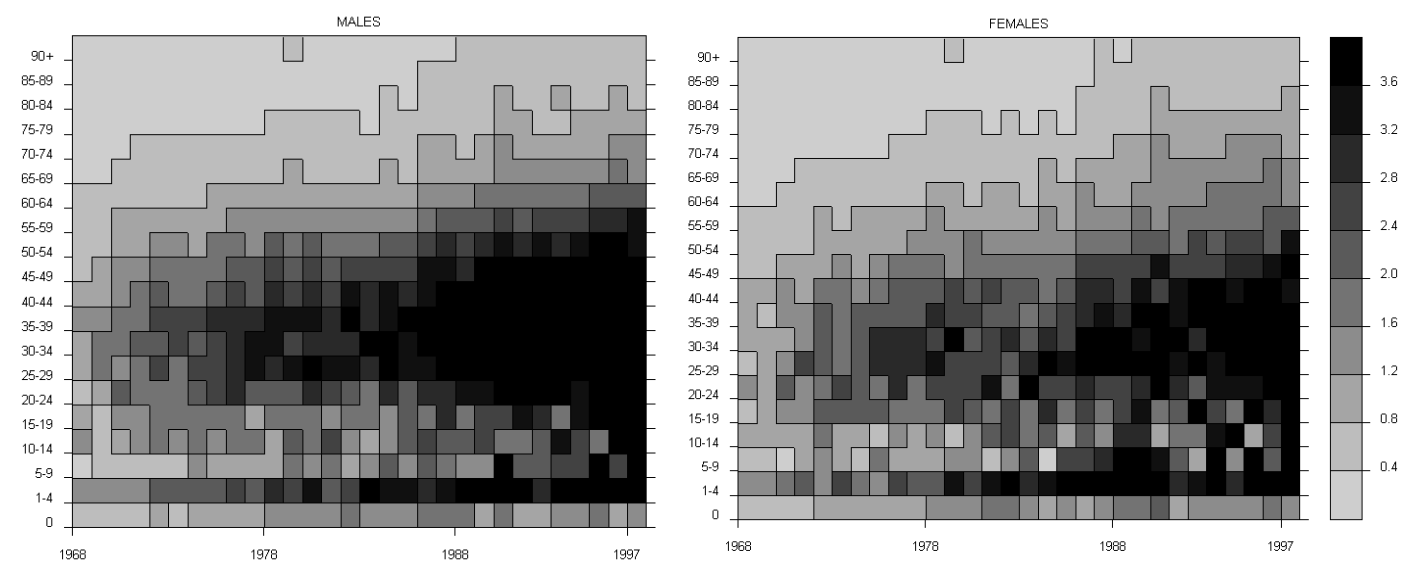

Figure 9 Lexis map of the proportions (\%) of ICD9 item $\mathbf{n}^{\circ}$ 799, Other unknown and ill-defined causes, from the total of deaths by age and year, 1968-1997

\section{RECONSTRUCTION OF CONTINUOUS TIME SERIES}

In West Germany, similarly to the majority of European countries, no double classification was produced at the time of change from the $8^{\text {th }}$ to the $9^{\text {th }}$ ICD revision, leading to the application of a method developed for the purpose of reconstructing time series in France for years 1925-1978, based on the creation of an a posteriori double classification (Vallin, Meslé 1988). The method consists of three steps. Firstly, a table of mutual correspondences between the medical content of each ICD item of the two successive revisions is created. Based on these correspondences, a list of elementary associations with identical medical and statistical ${ }^{17}$ content is created. The elementary associations serve as a basis for the estimation of transition coefficients the proportions of exchange between the linked ICD items from the old and the new cause-of-death classification. The resulting series then require further inspection. It is not exceptional that some of the defined correspondences need to be corrected either at the level of death counts summarized for all age groups or only for a specific age category.

\footnotetext{
${ }^{17}$ In many cases, the medical content of the association as defined by the correspondence table has to be modified in order to statistically balance the association.
} 
The reconstruction method itself cannot control for the ruptures in time series originating from the change in coding practices within one ICD revision, which can be sudden or gradual. The sudden changes in the coding practices, however, can be identified and corrected by exchanging a portion of deaths between the items in question within the framework of corrections a posteriori, performed during the last stage of the time-series creation.

\subsection{Correspondence tables}

At the moment of classification switch from the $8^{\text {th }}$ to the $9^{\text {th }}$ revision, WHO did not publish a document describing the changes in the classification and the correspondences (Vallin, Meslé 1998). Consequently, the correspondence tables have to be constructed via systematic comparison of the analytic tables and alphabetic indexes of the two respective classifications. The Statistical Office in West Germany created a hypothetical correspondence table adapted to the needs of the German tabulation system, ${ }^{18}$ which served as a basis for our work. ${ }^{19}$ However, many of these correspondences later on have proven to be insufficient and thus required large modifications.

A correspondence table consists of two symmetrical parts - the first one assigns to each item of ICD9 all items of the ICD8 of a common medical content. The second table then lists all mutual correspondences again, sorted by ICD8 items. Table 3 and Table 4 show a selection of the resulting initial correspondence tables.

\footnotetext{
${ }^{18}$ A machine-typed document entitled Umsteigeschlüssel für die Klassifikationen ICD 8. und 9. Revision, Statistisches Bundesamt, VII D, Wiesbaden, the $6^{\text {th }}$ December 1982.

${ }^{19}$ At this point, we would like to acknowledge Dr. Michael Bubenheim, who constructed the very first version of the correspondence tables and of the elementary associations.
} 
Table 3 Selected items of the correspondence table between ICD9 and ICD8

\begin{tabular}{|c|c|c|c|}
\hline \multicolumn{3}{|c|}{ ICD9 items } & \multirow{2}{*}{$\begin{array}{l}\text { ICD8 items } \\
\text { Title }\end{array}$} \\
\hline Code & Title & Code & \\
\hline 402 & Hypertensive heart disease & $\begin{array}{r}4001 \\
402 \\
412\end{array}$ & $\begin{array}{l}\text { Malignant hypertension with heart involvement } \\
\text { Hypertensive heart disease } \\
\text { Chronic ischemic heart disease }\end{array}$ \\
\hline 403 & Hypertensive renal disease & $\begin{array}{c}4003 \\
403\end{array}$ & $\begin{array}{l}\text { Malignant hypertension with renal involvement } \\
\text { Hypertensive renal disease }\end{array}$ \\
\hline$\ldots$ & $\ldots$ & $\ldots$ & $\ldots$ \\
\hline 410 & Acute myocardial infarction & 410 & Acute myocardial infarction \\
\hline 412 & Old myocardial infarction & $\begin{array}{l}412 \\
414 \\
429\end{array}$ & $\begin{array}{l}\text { Chronic ischemic heart disease } \\
\text { Asymptomatic ischemic heart disease } \\
\text { Ill-defined heart disease }\end{array}$ \\
\hline 413 & Angina pectoris & 413 & Angina pectoris \\
\hline 414 & Other forms of chronic ischemic heart disease & $\begin{array}{ll}412 \\
425 \\
\end{array}$ & $\begin{array}{l}\text { Chronic ischemic heart disease } \\
\text { Cardiomyopathy }\end{array}$ \\
\hline$\ldots$ & $\ldots$ & $\ldots$ & $\ldots$ \\
\hline 425 & Cardiomyopathy & $\begin{array}{l}425 \\
429\end{array}$ & $\begin{array}{l}\text { Cardiomyopathy } \\
\text { Ill-defined heart disease }\end{array}$ \\
\hline$\ldots$ & $\ldots$ & & $\ldots$ \\
\hline 429 & Ill-defined descriptions and complications of heart disease & $\begin{array}{l}412 \\
429 \\
\end{array}$ & $\begin{array}{l}\text { Chronic ischemic heart disease } \\
\text { Ill-defined heart disease }\end{array}$ \\
\hline$\ldots$ & $\ldots$ & $\ldots$ & $\ldots$ \\
\hline 417 & Other diseases of pulmonary circulation & $\begin{array}{l}426 \\
44 \mathrm{a} \\
441 \\
\end{array}$ & $\begin{array}{l}\text { Pulmonary heart disease } \\
\text { Remaining diseases of arteries, arterioles and capillaries } \\
\text { Aortic aneurysm (nonsyphilitic) }\end{array}$ \\
\hline$\ldots$ & $\ldots$ & $\ldots$ & $\ldots$ \\
\hline 442 & Other aneurysm & $44 \mathrm{a}$ & Remaining diseases of arteries, arterioles and capillaries \\
\hline 443 & Other peripheral vascular disease & $44 \mathrm{a}$ & Remaining diseases of arteries, arterioles and capillaries \\
\hline 446 & Polyarteritis nodosa and allied conditions & $44 a$ & Remaining diseases of arteries, arterioles and capillaries \\
\hline 447 & Other disorders of arteries and arterioles & $44 \mathrm{a}$ & Remaining diseases of arteries, arterioles and capillaries \\
\hline 448 & Disease of capillaries & $44 \mathrm{a}$ & Remaining diseases of arteries, arterioles and capillaries \\
\hline
\end{tabular}

Table 4 Selected items of the correspondence table between ICD8 and ICD9

\begin{tabular}{|c|c|c|c|}
\hline \multicolumn{3}{|c|}{ ICD8 items } & \multirow{2}{*}{$\begin{array}{l}\text { ICD9 items } \\
\text { Title }\end{array}$} \\
\hline Code & Title & Code & \\
\hline 4001 & Malignant hypertension with heart involvement & 402 & Hypertensive heart disease \\
\hline$\ldots$ & $\ldots$ & $\ldots$ & $\ldots$ \\
\hline 4003 & Malignant hypertension with renal involvement & 403 & Hypertensive renal disease \\
\hline$\ldots$ & $\ldots$ & $\ldots$ & $\ldots$ \\
\hline 402 & Hypertensive heart disease & 402 & Hypertensive heart disease \\
\hline 403 & Hypertensive renal disease & 403 & Hypertensive renal disease \\
\hline$\ldots$ & $\ldots$ & $\ldots$ & $\ldots$ \\
\hline 410 & Acute myocardial infrarction & 410 & Acute myocardial infarction \\
\hline$\ldots$ & $\ldots$ & $\ldots$ & $\ldots$ \\
\hline 412 & Chronic ischemic heart disease & $\begin{array}{l}402 \\
412 \\
414 \\
429\end{array}$ & $\begin{array}{l}\text { Hypertensive heart disease } \\
\text { Old myocardial infarction } \\
\text { Other forms of chronic ischemic heart disease } \\
\text { Ill-defined descriptions and complications of heart disease }\end{array}$ \\
\hline 413 & Angina pectoris & 413 & Angina pectoris \\
\hline 414 & Asymptomatic ischemic heart disease & 412 & Old myocardial infarction \\
\hline 425 & Cardiomyopathy & $\begin{array}{c}\ldots \\
414 \\
425 \\
\end{array}$ & $\begin{array}{l}\text { Other forms of chronic ischemic heart disease } \\
\text { Cardiomyopathy }\end{array}$ \\
\hline ... & $\ldots$ & $\ldots$ & $\ldots$ \\
\hline 429 & Ill-defined heart disease & $\begin{array}{l}412 \\
425 \\
429 \\
\end{array}$ & $\begin{array}{l}\text { Old myocardial infarction } \\
\text { Cardiomyopathy } \\
\text { Ill-defined descriptions and complications of heart disease }\end{array}$ \\
\hline$\ldots$ & $\ldots$ & $\ldots$ & $\ldots$ \\
\hline $44 a$ & Remaining diseases of arteries, arterioles and capillaries & $\begin{array}{l}417 \\
442 \\
443 \\
446 \\
447 \\
448\end{array}$ & $\begin{array}{l}\text { Other diseases of pulmonary circulation } \\
\text { Other aneurysm } \\
\text { Other peripheral vascular disease } \\
\text { Polyarteritis nodosa and allied conditions } \\
\text { Other disorders of arteries and arterioles } \\
\text { Disease of capillaries }\end{array}$ \\
\hline
\end{tabular}


Out of the selected correspondences between ICD9 and ICD8, ICD9 item $\mathrm{n}^{\circ} 410$, Acute myocardial infarction, represents the easiest case, where the entire content of one ICD9 item corresponds to one ICD8 item with the same code and the same title. The same applies to ICD9 item $n^{\circ} 413$, Angina pectoris. The ICD9 items $n^{\circ} 442-448$ link each to a single ICD8 item $\mathrm{n}^{\circ} 44 \mathrm{a}$, Remaining diseases of arteries, arterioles and capillaries. ${ }^{20}$ The remaining ICD9 items in the selected sample are related to multiple items of the $8^{\text {th }}$ ICD revision, for example the very first ICD9 item $n^{\circ} 402$, Hypertensive heart disease, which links with ICD8 items n 4001, 402 and 412.

\subsection{Elementary associations}

Some of the correspondences presented in Table 3 are only partial, meaning that one ICD8 item corresponds to several other ICD9 items. The table of correspondences between ICD8 and ICD9 (Table 4) is useful to identify such links. Searching for all possible links related to ICD9 item $\mathrm{n}^{\circ} 402$, we associate it with the total of deaths from ICD8 items $n^{\circ} 4001$ and 402 as they do not correspond to any other ICD9 item. ICD8 item $n^{\circ} 412$ then links with three other ICD9 items, which will be taken into account in the next step - the creation of elementary associations.

Elementary associations combine information from the correspondence table with the reported numbers of deaths in the transition years, i.e. the theoretical (medical) and empirical (statistical) content. The purpose is to create the smallest possible clusters of deaths by the same causes and to reclassify the deaths within each association.

There can be several types of associations, depending on the complexity of the changes between the two successive ICD revisions. In the easiest case, one ICD9 item corresponds to one ICD8 item, suggesting that no change in the definition took place between the two revisions. As the classification usually becomes more detailed in the next revision, many of the elementary associations link multiple ICD9 items with one ICD8 item, the latter item is thus split in order to form several ICD9 items Several ICD8 items join to form a single ICD9 item in rare cases. Such loss of classification detail on the 3-digit level was observed, for example, for a virtually eradicated disease: ICD9 item $\mathrm{n}^{\circ}$ 002, Typhoid and paratyphoid fever, which covered two items in ICD8: item $\mathrm{n}^{\circ} 001$, Typhoid fever and item $\mathrm{n}^{\circ} 002$, Paratyphoid fever. ${ }^{21}$ If details other than tabulation details are modified, the resulting associations are complex, linking several related ICD9 and ICD8 items.

We have constructed a total of 304 elementary associations. Table 5 shows the proportion of the associations by type. More than a half of the associations are simple correspondences $(1: 1)$. The second most frequent type represent complex associations $(\mathrm{N}: \mathrm{N})$, followed by the splitting of one ICD8 item into several ICD9 items (N:1). The following section demonstrates the construction of different types of associations

\footnotetext{
${ }^{20}$ As ICD8 items in West German statistics were often tabulated as groups, in the correspondence tables, associations and transition coefficients we use the alphanumeric working codes in order to facilitate the work. In this case, 44a substitutes a group of ICD8 3-digit items 442, 443, 446, 447, 448. The correspondence between the alphanumeric working codes and the real content of the items can be found in ANNEX 1 - CLASSIFICATION $\backslash$ ICD8.xls

${ }^{21}$ However, the distinction between these two was kept in ICD 9 on the 4-digit level.
} 
based on the correspondence tables, taking as example the items displayed in Table 3 and 4.

Table 5 Number of associations by type

\begin{tabular}{|lc|}
\hline \multicolumn{1}{|c|}{ Association type } & Number of associations \\
\hline Simple correspondence $(1: 1)$ & 175 \\
Splitting $(\mathrm{N}: 1)$ & 54 \\
Joining $(1: \mathrm{N})$ & 7 \\
Complex exchange $(\mathrm{N}: \mathrm{N})$ & 68 \\
\hline Total & 304 \\
\hline
\end{tabular}

To create an elementary association, both of the correspondence tables have to be searched. First, we look which ICD8 items correspond to the ICD9 item entering the association. We find e.g., a single ICD8 item corresponding to a single ICD9 item, as with ICD9 item $\mathrm{n}^{\circ} 410$, Acute myocardial infarction. The next step is to search the ICD8 to ICD9 correspondence table for other possible links of ICD8 item $n^{\circ} 410$. If no such links are found, the elementary association of Type 1:1 can be closed (see Table 6, Association $\mathrm{n}^{\circ} 141$ and Association $\mathrm{n}^{\circ} 143$ ).

Table 6 gathers all elementary associations that come out of the ICD items in Table 3 and Table 4. Each association contains information to identify the cause of death in question (i.e. ICD9 code and title), the identification of the corresponding items (ICD8 code and title), the death counts before and after the transition year, and the portion by which each ICD8 item corresponds to its ICD9 counterpart. The portion is designated as $\mathrm{T}$ (total) or $\mathrm{P}$ (partial), with $\mathrm{T}$ meaning that the total of ICD8 item will be associated with its ICD9 equivalent. If $\mathrm{P}$ is indicated, ICD8 will be split into several ICD9 items.

ICD9 item $\mathrm{n}^{\circ} 403$, Hypertensive renal disease, links with two ICD8 items: $\mathrm{n}^{\circ} 403$, Hypertensive renal disease, and 4003, Malignant hypertension with renal involvement. Checking against the correspondence table ICD8/ICD9 (Table 4), the ICD8 items in question both link with ICD9 403 only, creating a complete association of Type 1:N (see Table 6, Association $\mathrm{n}^{\circ} 139$ ).

Due to the frequent grouping of ICD8 items in the West German tabulation system, many correspondences, which would possibly be 1:1 if a full detail of the ICD8 have been published, were defined by splitting the grouped items into their ICD9 equivalents. The Association $\mathrm{n}^{\circ} 153$ represents such case, when a group of ICD8 items $n^{\circ} 442,443$ and 446-448 (44a) is split into individual ICD9 items $n^{\circ} 442,443$, and 446-448. 
Table 6 Examples of elementary associations

\section{Association $n^{\circ} 141$}

\begin{tabular}{|l|l|c|c|c|c|l|}
\hline \multicolumn{2}{|c|}{ ICD9 } & \multicolumn{2}{|c|}{ ICD8 } \\
\cline { 3 - 4 } Code & \multirow{2}{*}{ Title } & \multicolumn{2}{c|}{ Deaths in } & \multirow{2}{*}{ Code } & \multirow{2}{*}{ Portion } & \multirow{2}{*}{ Title } \\
\hline 410 & Acute myocardial infarction & 81121 & 79347 & 410 & $T$ & Acute myocardial infarction \\
\hline & & 81121 & 79347 & & & \\
\hline
\end{tabular}

\section{Association $\mathrm{n}^{\circ} 143$}

\begin{tabular}{|c|c|c|c|c|c|c|}
\hline \multirow{3}{*}{ Code } & \multicolumn{2}{|l|}{ ICD9 } & & & & ICD8 \\
\hline & \multirow{2}{*}{ Title } & \multicolumn{2}{|c|}{ Deaths in } & \multirow{2}{*}{ Code } & \multirow{2}{*}{ Portion } & \multirow{2}{*}{ Title } \\
\hline & & 1979 & 1978 & & & \\
\hline 413 & Angina pectoris & 1081 & 1024 & 413 & $\mathrm{~T}$ & Angina pectoris \\
\hline & Sum & 1081 & 1024 & & & \\
\hline
\end{tabular}

\section{Association $n^{\circ} 139$}

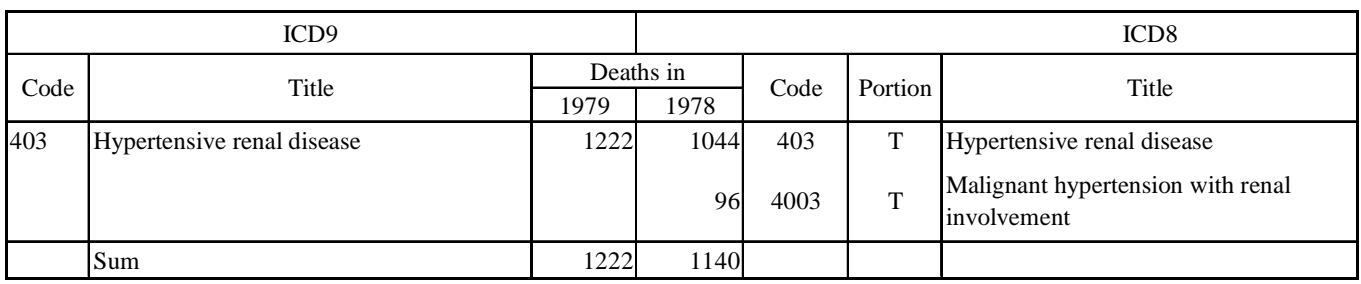

Association $n^{\circ} 153$

\begin{tabular}{|c|c|c|c|c|c|c|}
\hline \multicolumn{3}{|c|}{ ICD9 } & \multicolumn{4}{|r|}{ ICD8 } \\
\hline \multirow{2}{*}{ Code } & \multirow{2}{*}{ Title } & \multicolumn{2}{|c|}{ Deaths in } & \multirow{2}{*}{ Code } & \multirow{2}{*}{ Portion } & \multirow{2}{*}{ Title } \\
\hline & & 1979 & 1978 & & & \\
\hline 442 & Other aneurysm & 97 & 1100 & $44 a$ & $\mathrm{P}$ & $\begin{array}{l}\text { Remaining diseases of arteries, } \\
\text { arterioles and capillaries }(442,443,446-\end{array}$ \\
\hline 443 & Other peripheral vascular disease & 935 & & $44 \mathrm{a}$ & $\mathrm{P}$ & \\
\hline 446 & Polyarteritis nodosa and allied conditions & 78 & & $44 a$ & $P$ & \\
\hline 447 & Other disorders of arteries and arterioles & 60 & & $44 \mathrm{a}$ & $\mathrm{P}$ & \\
\hline 448 & Disease of capillaries & 18 & & $44 \mathrm{a}$ & $P$ & \\
\hline$(417)$ & (neglected) & & & (44a) & $\mathrm{P}$ & \\
\hline & Sum & 1188 & 1100 & & & \\
\hline
\end{tabular}

\section{Association $\mathrm{n}^{\circ} 138$}

\begin{tabular}{|c|c|c|c|c|c|c|}
\hline & ICD9 & & & & & ICD8 \\
\hline \multirow{2}{*}{ Code } & \multirow{2}{*}{ Title } & \multicolumn{2}{|c|}{ Deaths in } & \multirow{2}{*}{ Code } & \multirow{2}{*}{ Portion } & \multirow{2}{*}{ Title } \\
\hline & & 1979 & 1978 & & & \\
\hline \multirow[t]{3}{*}{402} & Hypertensive heart disease & 10693 & 9042 & 402 & $\mathrm{~T}$ & Hypertensive heart disease \\
\hline & & & 121 & 4001 & $\mathrm{~T}$ & Malignant hypertension with heart \\
\hline & & & 55126 & 412 & $\mathrm{P}$ & Chronic ischemic heart disease \\
\hline \multirow[t]{3}{*}{412} & Old myocardial infarction & 1301 & & 412 & $\mathrm{P}$ & \\
\hline & & & 2 & 414 & $\mathrm{~T}$ & Asymptomatic ischemic heart disease \\
\hline & & & 1507 & 429 & $\mathrm{P}$ & Ill-defined heart disease \\
\hline \multirow[t]{2}{*}{414} & $\begin{array}{l}\text { Other forms of chronic ischemic heart } \\
\text { disease }\end{array}$ & 37473 & & 412 & $P$ & \\
\hline & & & 378 & 425 & $\mathrm{P}$ & Cardiomyopathy \\
\hline \multirow[t]{2}{*}{429} & $\begin{array}{l}\text { Ill-defined descriptions and complications } \\
\text { of heart disease }\end{array}$ & 16861 & & & $\mathrm{P}$ & \\
\hline & & & & 429 & $\mathrm{P}$ & \\
\hline \multirow[t]{2}{*}{425} & Cardiomyopathy & 1036 & & $\begin{array}{l}425 \\
429\end{array}$ & $\begin{array}{l}\mathrm{P} \\
\mathrm{P}\end{array}$ & \\
\hline & Sum & 67364 & 66176 & & & \\
\hline
\end{tabular}


Association $\mathrm{n}^{\circ} 138$ (Table 6) is more complex. ICD8 item $\mathrm{n}^{\circ} 402$, Hypertensive heart disease, and ICD8 item $\mathrm{n}^{\circ} 4001$, Malignant hypertension with heart involvement, do not provide enough deaths to compensate for ICD9 item $\mathrm{n}^{\circ} 402$ and therefore ICD8 item $\mathrm{n}^{\circ} 412$ Chronic ischemic heart disease enters the association. According to the ICD8 to ICD 9 correspondence table, ICD8 item $n^{\circ} 412$ links with three other ICD9 items: $n^{\circ} 412, n^{\circ} 414$, and $n^{\circ} 429$. The correspondences of ICD9 item $n^{\circ} 412$ bring ICD8 items $n^{\circ} 414$ and $n^{\circ} 429$ into the same association. Out of these, ICD 9 item $n^{\circ}$ 414 also corresponds to ICD8 item $n^{\circ} 425$, linked with another ICD9 item - $n^{\circ} 425$ Cardiomyopathy, Complex associations are thus a mixture of splitting and joining several cross-linked ICD items.

During the construction of an elementary association, its statistical coherence is taken into account, too. It can thus happen that the associations do not contain all links from the correspondence tables or some new links have to be defined. In Association $\mathrm{n}^{\circ}$ 153, the link of ICD9 item $n^{\circ} 417$ with ICD8 item $n^{\circ} 44$ a was neglected, because the association already seems to be equilibrated and because the general purpose is to obtain the smallest possible associations.

Before proceeding to the next step, the statistical continuity of the associations is checked and assured. We have looked up the sums of all associations through the years 1968 to 1997. If the rupture in the transition year exceeded the amplitude of a normal fluctuation within one ICD revision, the correspondences were revisited and eventually corrected by adding or neglecting some links.

\subsection{Transition coefficients}

The task yet remains to redistribute the deaths in each association by means of transition coefficients.

In simple associations (1:1) $100 \%$ of the old item correspond to the new item. Also, if several ICD9 items join to form one ICD8 item, 100\% of each ICD9 item joins to obtain the respective ICD8 item, a simple sum of all ICD9 items in question. Inversely, if ICD9 is redistributed to the ICD8 structure, the ICD8 item is divided proportionally to the distribution of the ICD9 items in 1979.

If one ICD9 item splits into several ICD8 items, the hypothetical distribution of deaths in 1978 according to ICD9 is obtained by applying the proportions of ICD8 items in 1978 to the death counts from the ICD9 item in 1979. Vice versa, to obtain the ICD9 distribution in 1978 and backwards, we simply summarize $100 \%$ of each ICD8 item entering the association.

The changes described so far reflect a change in the level of the classification detail. The following description refers to one of the 68 cases where we dealt with complex exchanges between the items. Using Association $\mathrm{n}^{\circ} 138$ as an example, we will demonstrate how to estimate the percentages of death count exchange between the respective items. To do so, we first construct a double classification cross-table (Table 7).

Table 7 Double classification cross-table to redistribute deaths in the transition years 1978 and 1979 


\begin{tabular}{|c|c|c|c|c|c|c|c|}
\hline \multirow{2}{*}{$\begin{array}{c}\text { Items of } \\
\text { ICD9 }\end{array}$} & \multicolumn{6}{|c|}{ Items of ICD8 } & \multirow{2}{*}{$\begin{array}{c}\text { Deaths in } \\
1979\end{array}$} \\
\hline & 402 & 4001 & 412 & 414 & 425 & 429 & \\
\hline 402 & 9204 & 123 & 1366 & & & & 10693 \\
\hline 412 & & & 1120 & 2 & & 179 & 1301 \\
\hline 414 & & & 37218 & & 255 & & 37473 \\
\hline 425 & & & & & 130 & 906 & 1036 \\
\hline 429 & & & 16412 & & & 449 & 16861 \\
\hline 1979 (estimate) & 9204 & 123 & 56116 & 2 & 385 & 1534 & 67364 \\
\hline 1978 (real) & 9042 & 121 & 55126 & 2 & 378 & 1507 & 66176 \\
\hline
\end{tabular}

In the beginning, we dispose only with the death counts observed in 1978 classified under ICD8 and in 1979 classified under ICD9. We calculate the hypothetical distribution of the deaths in 1979 according to the proportions observed in 1978 under the assumption that the distribution remained constant in the association in years 1978 and 1979. The core of the method is to redistribute the deaths inside the cross-table. As the shaded areas mean there is no correspondence between the two items, the non-shaded areas have to be filled. A total (100\%) of ICD8 item $\mathrm{n}^{\circ} 402$ and ICD8 item $n^{\circ} 4001$ is distributed to ICD9 item $n^{\circ} 402$ and a total of ICD8 item $n^{\circ} 414$ to ICD9 item $n^{\circ} 412$. To obtain the portion of ICD8 item $n^{\circ} 412$, that forms the rest of ICD9 item $\mathrm{n}^{\circ} 402$, we simply subtract the known death counts from the death counts observed in $1979(10693-9204-123=1366)$. In some associations, only one crossclassification is possible. The selected example represents a case in which several redistribution variants are possible, as we cannot directly estimate the cross-classification of ICD8 items $n^{\circ} 412,425$, and 429. Here, we decided to first redistribute the deaths from the ICD9 items $n^{\circ} 414$ and 429 proportionally to the hypothetical death counts of the corresponding ICD8 items estimated for 1979 and to fill the remainder of the table by subtraction.

Table 8 Transition coefficients between ICD9 and ICD8

\begin{tabular}{|c|c|c|c|c|c|c|c|}
\hline \multirow{2}{*}{$\begin{array}{l}\text { Items of } \\
\text { ICD9 }\end{array}$} & \multicolumn{6}{|c|}{ Items of ICD8 } & \multirow{2}{*}{ Sum } \\
\hline & 402 & 4001 & 412 & 414 & 425 & 429 & \\
\hline 402 & 0.861 & 0.012 & 0.128 & & & & 1.000 \\
\hline 412 & & & 0.861 & 0.002 & & 0.138 & 1.000 \\
\hline 414 & & & 0.993 & & 0.007 & & 1.000 \\
\hline 425 & & & & & 0.125 & 0.875 & 1.000 \\
\hline 429 & & & 0.973 & & & 0.027 & 1.000 \\
\hline
\end{tabular}

The table of transition coefficients (Table 8) is then directly derived from the completed cross table (Table 7). They can be calculated in two ways, either by redistributing the content of the ICD8 items to ICD9 or vice versa. The decision was made to define the transition coefficients that redistribute ICD9 to ICD8. This approach enables us to benefit from the fact that ICD9 is more detailed than is ICD8, and it is also based on previous experience from the French reconstruction (Vallin, Meslé 1998). 


\subsection{Reconstructing time series - final steps}

As explained above, the transition coefficients serve to redistribute ICD9 to ICD8. We defined the transition coefficients between ICD9 and ICD8 manually from the correspondence tables and from the cross-tables, neither distinguishing age group nor the sex. Using these coefficients, we reclassified the deaths from the three post-transition years (1979-1981) under ICD8. Based on this cross tabulation, we calculated the coefficients of transition from ICD8 to ICD9 by age group and sex. These coefficients were applied to calculate the time series between 1968 and 1978 .

The following figures demonstrate how the series look before and after applying the transition coefficients. Figure 10- Figure 12 show the reconstruction of the items discussed in the previous chapters.
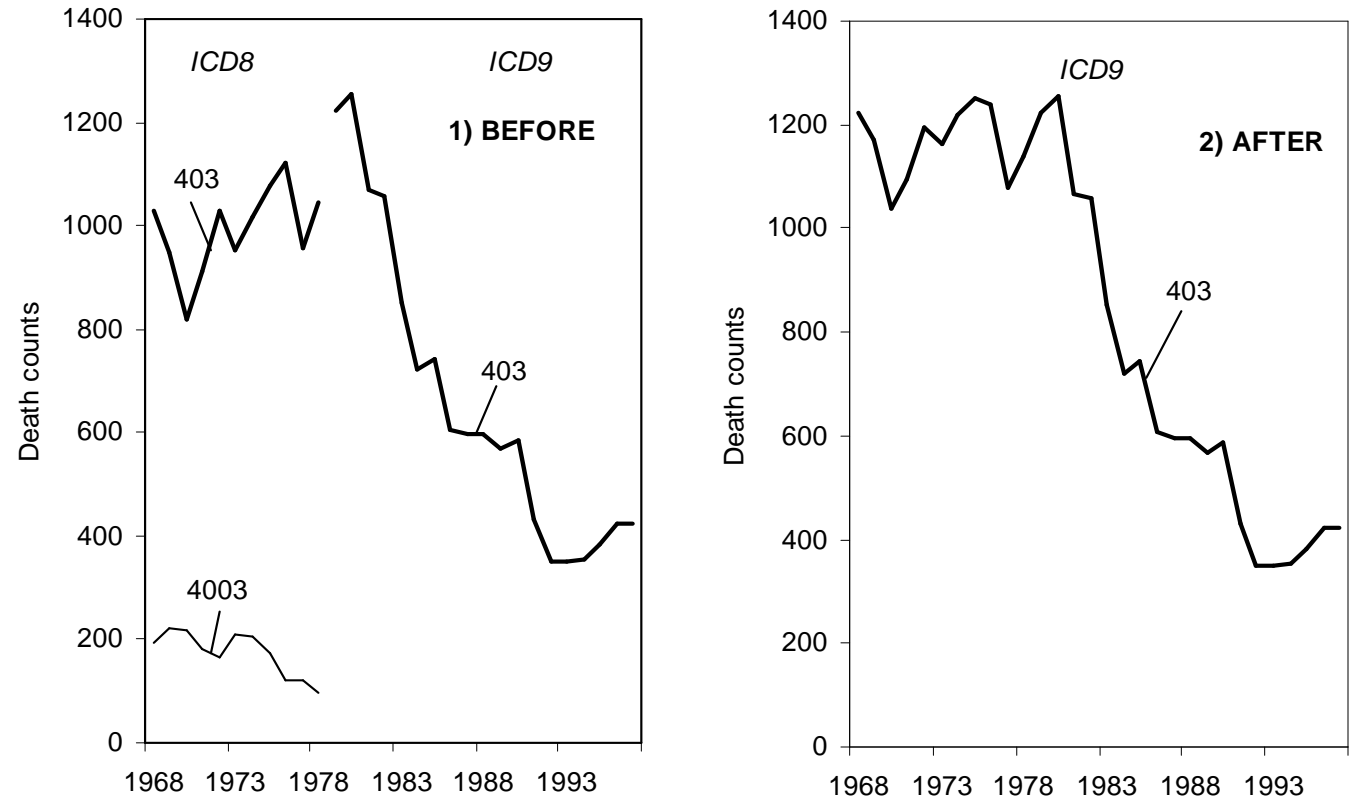

Figure 10 Example of the elementary association before and after the reconstruction. Association $\mathbf{n}^{\circ} 139$

ICD8 items (1968-1978)

403 Hypertensive renal disease

4003 Malignant hypertension with renal involvement
ICD9 items (1979-1997)

403 Hypertensive renal disease

In Figure 10, the series for ICD9 item $\mathrm{n}^{\circ} 403$, Hypertensive renal disease, is created by a simple sum of ICD8 items $n^{\circ} 403$ and 4003, while most of the content comes from ICD8 item $n^{\circ} 403$. Even though the curve is not perfectly smooth, the rupture at the time of the classification change does not exceed the fluctuations observed in ICD8.

Association $n^{\circ} 153$ deals with diseases of arteries, arterioles, and capillaries and is displayed in Figure 11. The grouped ICD8 item $\mathrm{n}^{\circ} 44 \mathrm{a}$, Remaining diseases of 
arteries, arterioles and capillaries, splits to form several items according to ICD9. The major part of ICD8 item $\mathrm{n}^{\circ} 44 \mathrm{a}$ is attributed to ICD9 ICD8 item $\mathrm{n}^{\circ} 443$, Other peripheral vascular disease, - a cause of death that showed an exemplary decline since the 1980s, while the death counts from the remaining causes of this association were stable over the entire period.
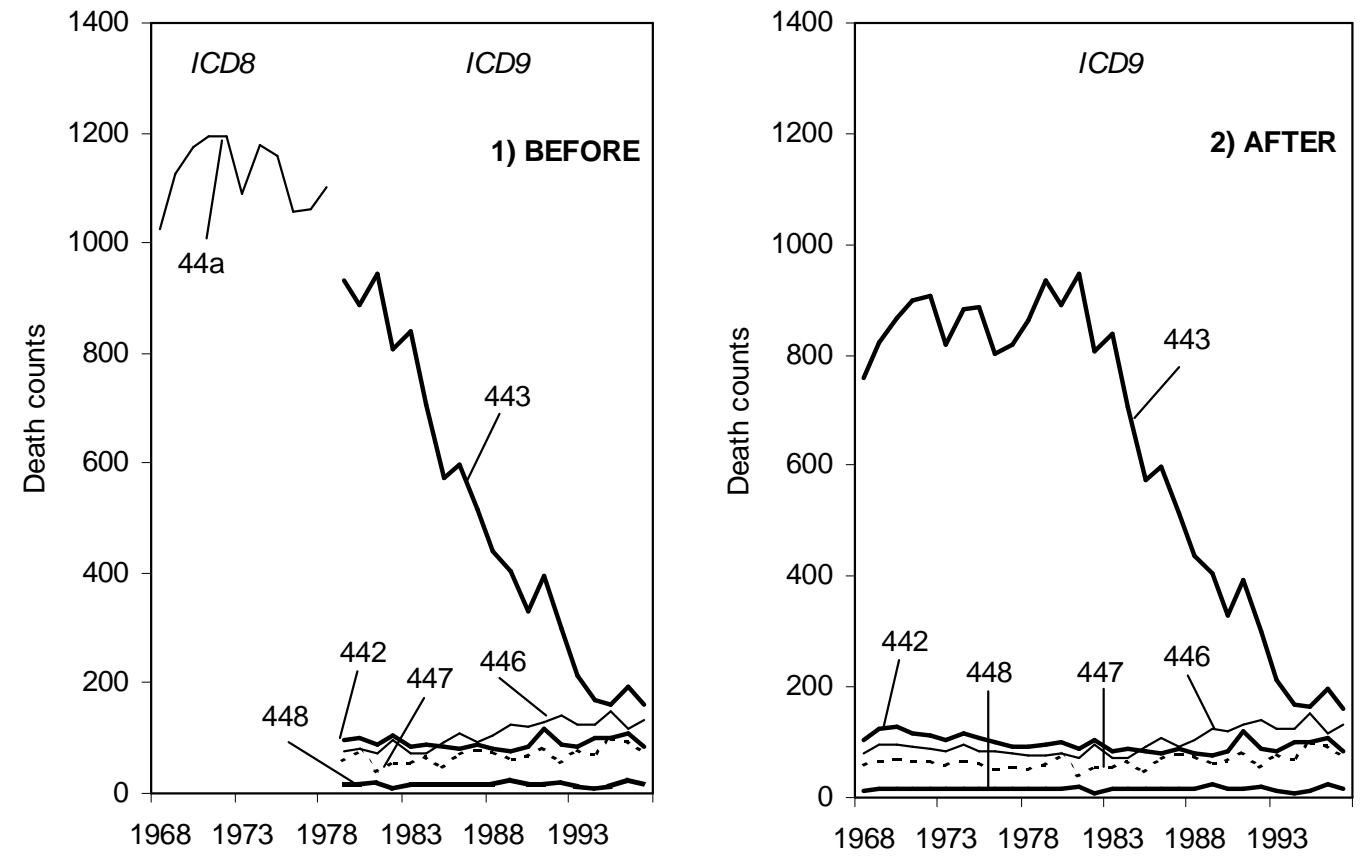

Figure 11 Example of the elementary association before and after the reconstruction. Association $n^{\circ} 153$

ICD8 items (1968-1978)

44a Remaining diseases of arteries, arterioles, and capillaries
ICD9 items (1979-1997)

442 Other aneurysm

443 Other peripheral vascular disease

446 Polyarteritis nodosa and allied conditions

447 Other disorders of arteries and arterioles

448 Disease of capillaries

The first example of a complex association is represented in Figure 12. The main item here is ICD9 item $\mathrm{n}^{\circ} 414$, Other forms of ischemic heart disease, one of the most important single causes of death per se. ICD8 item $\mathrm{n}^{\circ} 412$, Chronic ischemic heart disease, provides the decisive part of deaths for ICD9 item $\mathrm{n}^{\circ} 414$. The remainder of the 55126 deaths from ICD8 item $\mathrm{n}^{\circ} 412$ in 1978 was distributed primarily to ICD9 item $\mathrm{n}^{\circ} 429$, Ill-defined heart disease, and helped to level off the rupture between item $\mathrm{n}^{\circ} 402$ in ICD8 and ICD9. 

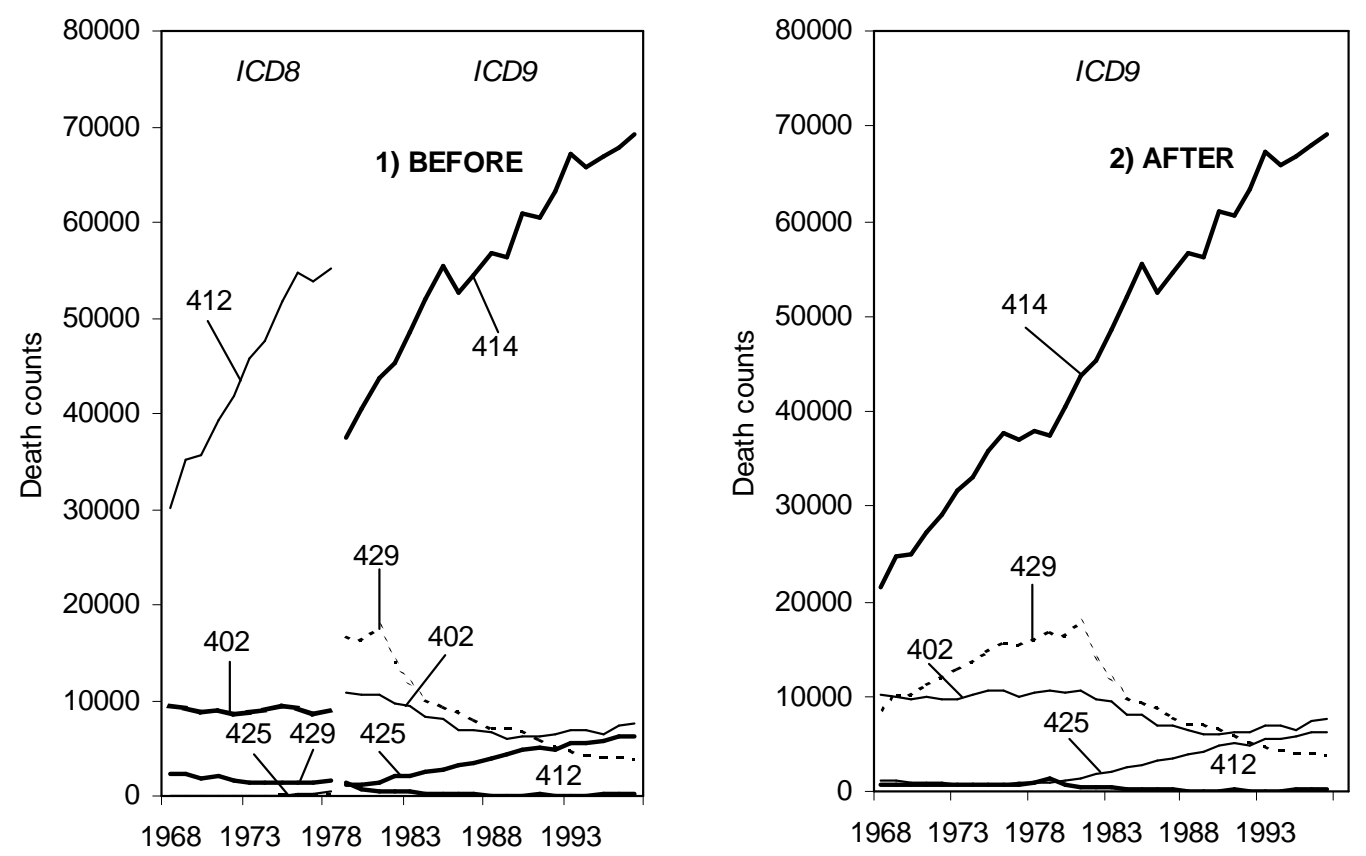

Figure 12 Example of the elementary association before and after the reconstruction. Association $\mathbf{n}^{\circ} 138$

ICD8 items (1968-1978)

402 Hypertensive heart disease

4001 Malignant hypertension with heart involvement

412 Chronic ischemic heart disease

414 Asymptomatic ischemic heart disease

425 Cardiomyopathy

429 Ill-defined heart disease

ICD9 items (1979-1997)

402 Hypertensive heart disease

412 Old myocardial infarction

414 Other forms of chronic ischemic heart disease

425 Cardiomyopathy

429 Ill-defined descriptions and complications of heart disease

Figure 13 shows the reconstruction of another complex association, not mentioned earlier. Association $\mathrm{n}^{\circ} 80^{22}$ deals primarily with ICD9 item $\mathrm{n}^{\circ} 191$, Malignant neoplasm of brain. ICD8 item $\mathrm{n}^{\circ}$ 191, Malignant neoplasm of brain, could hardly compensate for the neoplasms of brain classified under ICD9 item $\mathrm{n}^{\circ} 191$. The missing deaths from this neoplasm, as defined by ICD9, were found under ICD8 item $\mathrm{n}^{\circ} 192$, Malignant neoplasm of other parts of nervous system.

\footnotetext{
${ }^{22}$ For a detailed content of this association, see ANNEXI 2 - TRANSITION BETWEEN ICD8 AND ICD9lelementary associations.
} 

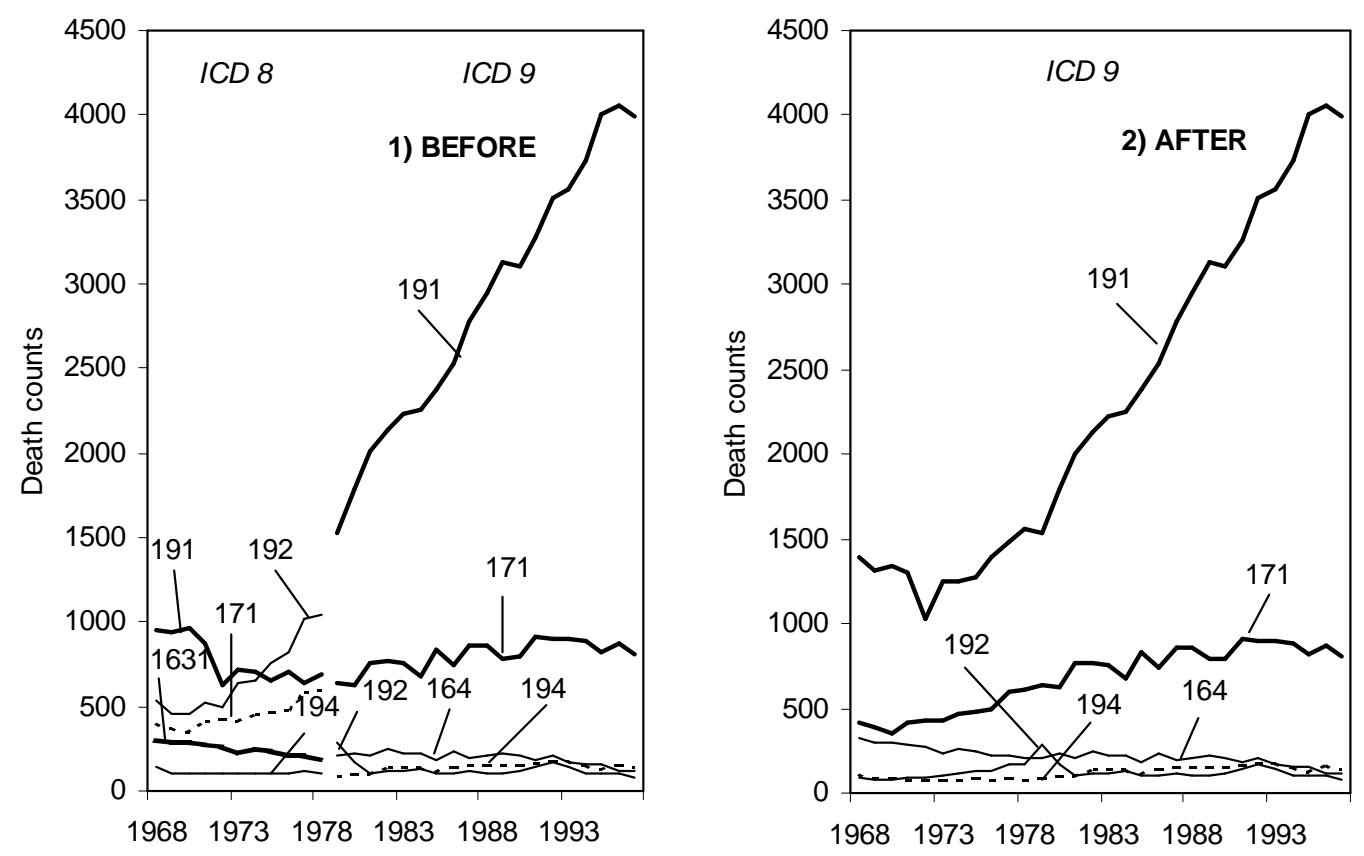

Figure 13 Example of the elementary association before and after the reconstruction. Association $\mathbf{n}^{\circ} 80$

\section{ICD8 items (1968-1978)}

1631 Malignant neoplasm of mediastinum

171 Malignant neoplasm of connective and other soft tissue

191 Malignant neoplasm of brain

192 Malignant neoplasm of other part of nervous system

194 Malignant neoplasm of other endocrine glands
ICD9 items (1979-1997)

164 Malignant neoplasm of thymus, heart, and mediastinum

171 Malignant neoplasm of connective and other soft tissue

191 Malignant neoplasm of brain

192 Malignant neoplasm of other and unspecified parts of nervous system

194 Malignant neoplasm of other endocrine glands and related structures

A disturbing rupture appeared in 1979 for ICD9 item $n^{\circ} 192$, when the death counts increased from 168 in 1978 to 288 in 1979 and then fell to 175 in 1980. At the same time, the death counts from ICD9 item $\mathrm{n}^{\circ} 191$ decreased by 33 between 1978 and 1979 in spite of a continuous increase that set in the mid-1970s. It is likely that the rupture is due to an initial misunderstanding regarding the coding manners for this disease: Part of the deaths were coded in the "old way", i.e. under the equivalent of ICD8 item $n^{\circ} 192$.

Another rupture came out in 1972, under ICD8. Due to a sudden drop in death counts, the trend of the reconstructed ICD9 item $\mathrm{n}^{\circ} 191$ exhibited a visible depression in 1972. Unlike the rupture in 1979, the compensatory deaths cannot be found in this association and we have to look for them elsewhere.

The method applied so far can only solve the discontinuities related to the change of the classification. The example of Association $\mathrm{n}^{\circ} 80$ points at another problem specific to the cause-of-death time-series: the changes in the coding practices, which 
can appear at any moment of the current classification. This issue will be addressed to greater detail in Section 3.5.

\subsubsection{Age-specific treatment of time series}

In rare cases, the transitions are valid only for specific age groups. In the case of West Germany, several items are associated differently for age 0 than they are for higher age. Thus, we found out that in Association $n^{\circ} 59^{23}$ part of the infant deaths from ICD9 item $\mathrm{n}^{\circ} 136$, Other and unspecified infectious and parasitic diseases, was previously in ICD8 classified under item $\mathrm{n}^{\circ} 00 \mathrm{a}$, Remaining infectious intestinal diseases (which groups items $\mathrm{n}^{\circ} 008$, Intestinal infections, and 009, Ill-defined intestinal infections). Similarly, a portion of infant deaths from ICD8 items $\mathrm{n}^{\circ} 008$ and 009 and of infant deaths from ICD8 item $\mathrm{n}^{\circ} 07 \mathrm{a}$, Remaining viral diseases, (group of ICD8 items $\mathrm{n}^{\circ}$ 071, 074-079) was associated with ICD9 item $\mathrm{n}^{\circ} 771$, Infections specific to perinatal period, only for age 0 .

Another such case represents Association $\mathrm{n}^{\circ} 119^{24}$, where the link between ICD9 item $\mathrm{n}^{\circ} 767$, Birth trauma, and ICD8 item $\mathrm{n}^{\circ} 343$, Cerebral spastic infantile paralysis, is valid only for age 0 . In the same association, a problem occurred also for ICD9 item $\mathrm{n}^{\circ} 798$, Sudden death of unknown cause, where the infant deaths from ICD8 items $\mathrm{n}^{\circ} 795,78 \mathrm{~b}$ and $79 \mathrm{a}$ could not compensate for the deaths observed after the classification change. To address this rupture, we have linked ICD8 item $\mathrm{n}^{\circ} 776$, Anoxic and hypoxic conditions not elsewhere classifiable, with ICD9 item $\mathrm{n}^{\circ} 798$, Sudden death of unknown cause, only for age 0. The transition coefficients were then calculated separately for age 0 and for the remaining age groups.

In Association $\mathrm{n}^{\circ} 239^{25}$, excess deaths in the first year of life from ICD8 item $\mathrm{n}^{\circ} 254$, Diseases of thymus gland, were observed, while for age above 0, the ICD8 item $\mathrm{n}^{\circ} 254$ is linked to $100 \%$ with ICD9 item $\mathrm{n}^{\circ} 254$. We have looked for the new placement of infant deaths classified under ICD8 item $\mathrm{n}^{\circ} 254$ and we found them under ICD9 item $\mathrm{n}^{\circ} 759$, Other and unspecified congenital anomalies. We assume that for this disease the coding manners changed along with the classification change. However, according to the correspondence tables released by the German Statistical Office, there should be a $100 \%$ correspondence between the Diseases of thymus gland in ICD8 and ICD9.

Figure 14 shows how the series look before and after the reconstruction, with the adjustment made to age 0. If we adopt the recommendation of the German Statistical Office and associate ICD9 item $\mathrm{n}^{\circ} 254$ solely with ICD8 item $\mathrm{n}^{\circ} 254$, a remarkable rupture would disturb the series (see Figure 14 "Age 0 Before"). Due to an adjustment to age 0 , the resulting series are smooth: The link was set up in such a way as to assure that $13.5 \%$ of ICD9 item $\mathrm{n}^{\circ} 759$ will be formed by ICD 8 item $\mathrm{n}^{\circ} 254$ at age 0 , while for higher age groups the entire content (100\%) of ICD8 item $\mathrm{n}^{\circ} 254$ is distributed to ICD9 item $\mathrm{n}^{\circ} 254$.

\footnotetext{
${ }^{23}$ For detailed content of this association see ANNEX 2 - TRANSITION BETWEEN ICD8 AND ICD9\Elementary associations.

${ }^{24}$ For detailed content of this association see ANNEX 2 - TRANSITION BETWEEN ICD8 AND ICD9\Elementary associations.

${ }^{25}$ For detailed content of this association see ANNEX 2 - TRANSITION BETWEEN ICD8 AND ICD9\Elementary associations.
} 

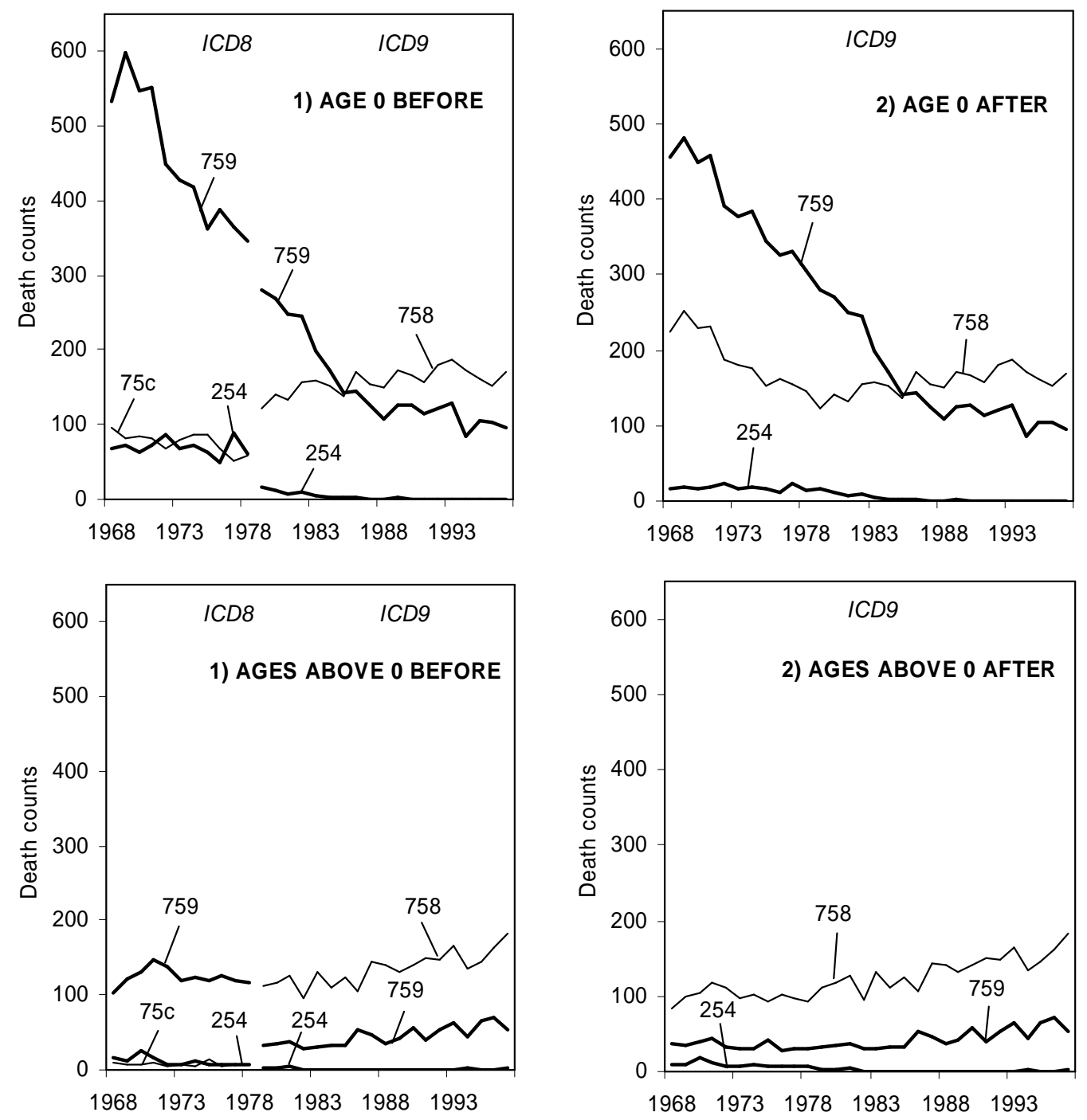

Figure 14 Example of the elementary association before and after the reconstruction, including the adjustment for age 0 . Association $\mathbf{n}^{\circ} 239$

ICD8 items (1968-1978)

254 Diseases of thymus gland

75c Other and unspecified congenital anomalies

759 Congenital syndromes affecting multiple systems
ICD9 items (1979-1997)

254 Diseases of thymus gland

758 Chromosomal anomalies

759 Other and unspecified congenital anomalies 
With the remaining items, we assume for the first version of the transition coefficients that the exchanges took place in all age groups with the same proportion. Nevertheless, the experience from France (Vallin, Meslé, 1987) and Russia (Meslé et al. 1996) has shown that the change in the classification can be accompanied by a change in the coding practices related to certain age groups only. To identify and correct such ruptures, we examined the time series by 5 -year age groups.

Apart from the inconsistencies for the first year of life described above and addressed previously at the level of the elementary associations, other causes of death were found to be inconsistent by age. This was the case of items from Association $n^{\circ} 103^{26}$ dealing with neoplasms without further specification of site or behaviour. While checking the series by age, it appeared that for age groups 35-39 to 75-79 the original transition coefficients, estimated from the total of all age groups, attributed too many deaths to ICD9 item $\mathrm{n}^{\circ}$ 238, Neoplasm of uncertain behaviour of other and unspecified sites and tissues, while these deaths were systematically missing in the ICD9 item $n^{\circ} 239$, Neoplasms of unspecified nature. The situation reversed after age group 75-79. At age groups below 35-39, the death counts were too few to reflect this change in the coding practices.

The association contained several complex exchanges, which led us to the estimation of transition coefficients from the cross tables for all age groups above 35-39 individually. Figure 15 represents both situations (i.e. before and after age 75-79), both before and after the age specific correction of transition coefficients. This was a rare case, similar adjustments by age were made only in three other items. ${ }^{27}$

\footnotetext{
${ }^{26}$ For a detailed content of this association, see ANNEX 2 - TRANSITION BETWEEN ICD8 AND ICD9\Elementary associations

${ }^{27}$ For details, see ANNEX 2 - TRANSITION BETWEEN ICD8 AND ICD9\Transition coefficients
} 

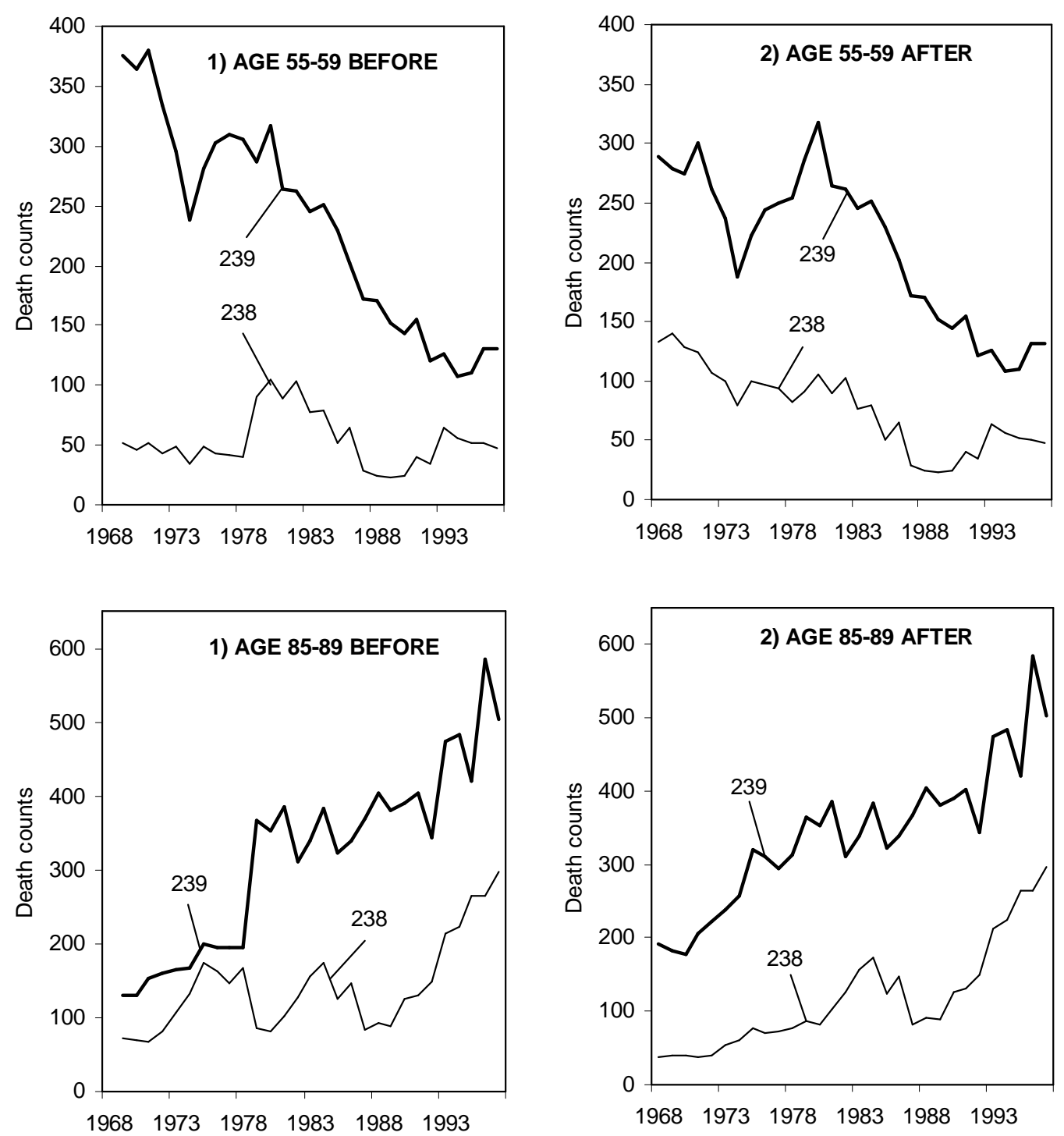

Figure 15 Results of the application of age-specific corrected transition coefficients. Association $\mathbf{n}^{\circ} \mathbf{1 0 3}$

ICD9 238 Neoplasm of uncertain behaviour of other and unspecified sites and tissues

ICD9 239 Neoplasms of unspecified nature

\subsection{Beyond the classification changes}

The study of cause-of-death patterns is not only facing the discontinuities introduced at the time of the classification change. As suggested by the last example of the previous chapter, numerous ruptures can occur suddenly within one revision due to the application of new coding instructions. Such ruptures are usually easily identified by inspecting the time series. They are corrected as follows. 


\subsubsection{Unique case of the emergence of AIDS}

AIDS is the first example selected to demonstrate how the series were treated after the reconstruction. First deaths from AIDS emerged in the early 1980s and in the next few years the infection became a serious worldwide health threat. There was no category for AIDS in the original version of ICD9, but as there was an acute need of AIDS mortality surveillance, WHO accepted for the very first time in the history of ICD to modify the classification before the release of the new revision. It did so in 1986 when releasing an addendum to the $9^{\text {th }}$ revision (WHO 1986). Three new 3-digit items were assigned to distinguish different forms of AIDS, namely item $\mathrm{n}^{\circ}$ 042, Human immunodeficiency virus [HIV] disease, item $\mathrm{n}^{\circ}$ 043, AIDS-related complex (ARC), and item $\mathrm{n}^{\circ}$ 044, Other HIV infection. However, not all countries adopted this addendum when it was published. In West Germany, the new items entered in the tabulation as of 1989, following the recommendations of the CDC (Centres for Disease Control) (CDC 1987).

In many countries, deaths involving HIV infection prior to the addendum were classified mainly under ICD9 item $\mathrm{n}^{\circ} 279.1$, Deficiency of cell-mediated immunity (Vallin, Meslé 1998) but also under malignant neoplasms, including neoplasms of lymphatic and haematopoietic tissues, and possibly under a number of other causes. Finding these misclassified deaths prior to 1989 thus creates a more accurate series of AIDS mortality.

Most of the deaths related to HIV infection in West Germany were previously classified under ICD9 item $\mathrm{n}^{\circ} 136$ Other and unspecified infectious and parasitic diseases; item $\mathrm{n}^{\circ} 279$ showed only a minor increase in death counts. Figure 16 confirms that the increase in death counts in ICD9 item $\mathrm{n}^{\circ} 136$ between 1984 and 1989 is due to the emergence of a new disease and quantitatively and qualitatively corresponds to misclassified deaths from AIDS. ${ }^{28}$ We redistributed the excess deaths from ICD9 item $n^{\circ} 136$ to the three new items, extrapolating the series backwards by 5 -year age groups. The resulting pattern provides a more accurate image of the actual AIDS mortality in West Germany, as well as the correct trend for ICD9 item $n^{\circ} 136$ Other and unspecified infectious and parasitic diseases.

\footnotetext{
${ }^{28}$ Moreover, the analysis of these deaths by age confirmed that the excess deaths in ICD9 136 in 1984-1988 correspond to the age structure of deaths from AIDS as coded later in ICD9 042-044, i.e. with maximum mortality at ages 20-24 to 40-44.
} 

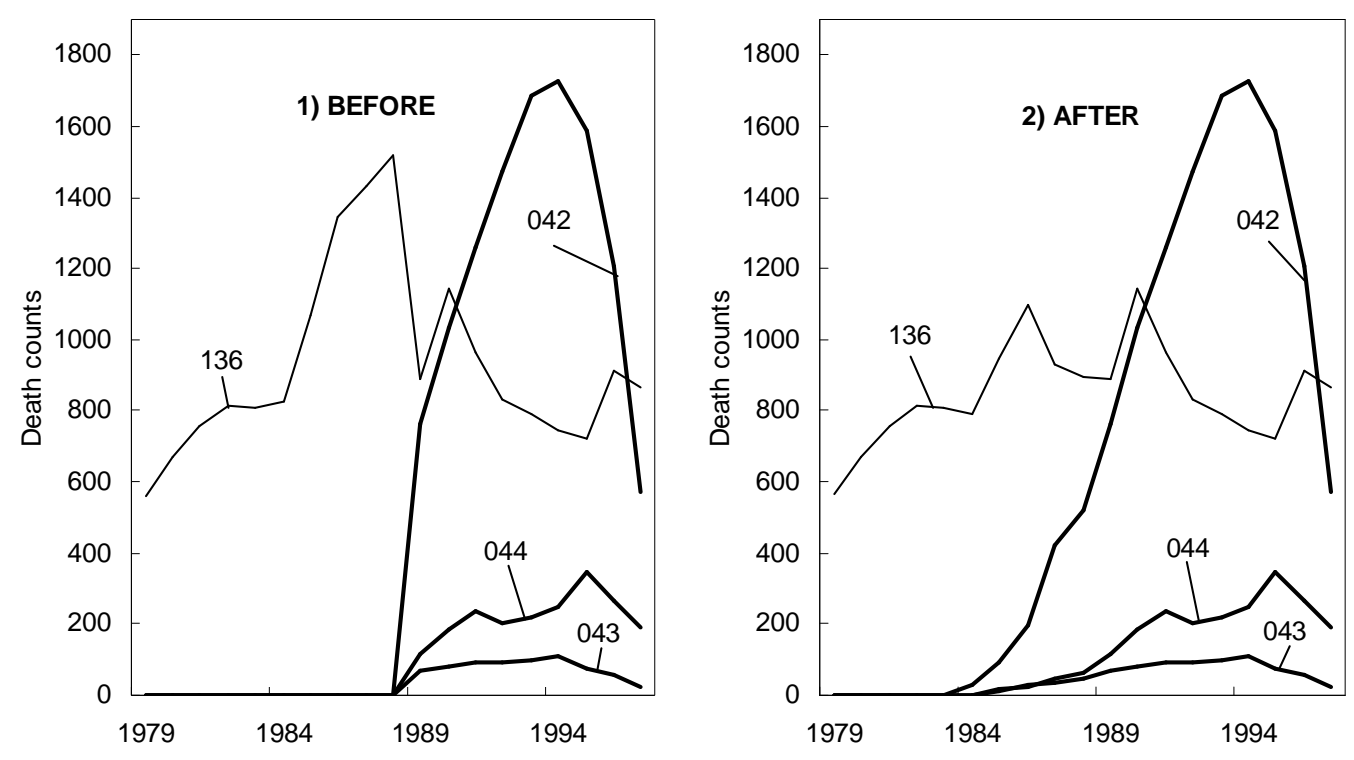

Figure 16 Number of deaths related to HIV infection before and after correction $a$ posteriori

ICD9 items:

042 Human immunodeficiency virus [HIV] disease

043 AIDS-related complex (ARC)

044 Other HIV infection

136 Other infectious and parasitic diseases

The correction related to AIDS mortality is a very complex exchange between the ICD items. Most of the excess content of the ICD9 item $\mathrm{n}^{\circ} 136$ was assigned to item $\mathrm{n}^{\circ}$ 042. The corrections were limited to age 15-64, but the maximum toll of transferred deaths were in age group 25-49 and the transfers increased with time. Thus, in 1988 more than $98 \%$ of the content of ICD9 item $n^{\circ} 136$ in age group 30-39 was moved to the AIDS-related ICD9 items n $042-044$.

\subsubsection{Sudden changes in coding practices}

Apart from AIDS-related exchanges, another 16 ICD9 items were changed after the redistribution by means of transition coefficients. We will focus on three exchanges in more detail.

In West Germany, many ruptures subject to corrections a posteriori occurred in the years close to the classification change, suggesting that there were initial discordances related to the adoption of the new revision and its coding rules.

The first example (Figure 17) solves the problem of Association $n^{\circ} 80$ discussed in the previous chapter, i.e. the excess of deaths in item $\mathrm{n}^{\circ} 192$ against the depression of the death counts in the item $\mathrm{n}^{\circ} 191$ in 1979, and a sudden decrease in death counts from ICD9 item $n^{\circ} 191$, Malignant neoplasm of brain, in 1972. In 1979, the problem was identified in age groups 25-79 and 20\%-50\% (according to age) of the deaths were transferred from item $\mathrm{n}^{\circ} 192$ to item $\mathrm{n}^{\circ} 191$ (Table 9). In 1972, the corresponding excessive deaths in age groups 50-54 to 70-74, where the deaths were 
missing in the item $\mathrm{n}^{\circ} 191$, were only found in the group of ill-defined cancers, i.e. the reconstructed ICD9 item $\mathrm{n}^{\circ} 239$ Neoplasms of unspecified nature.
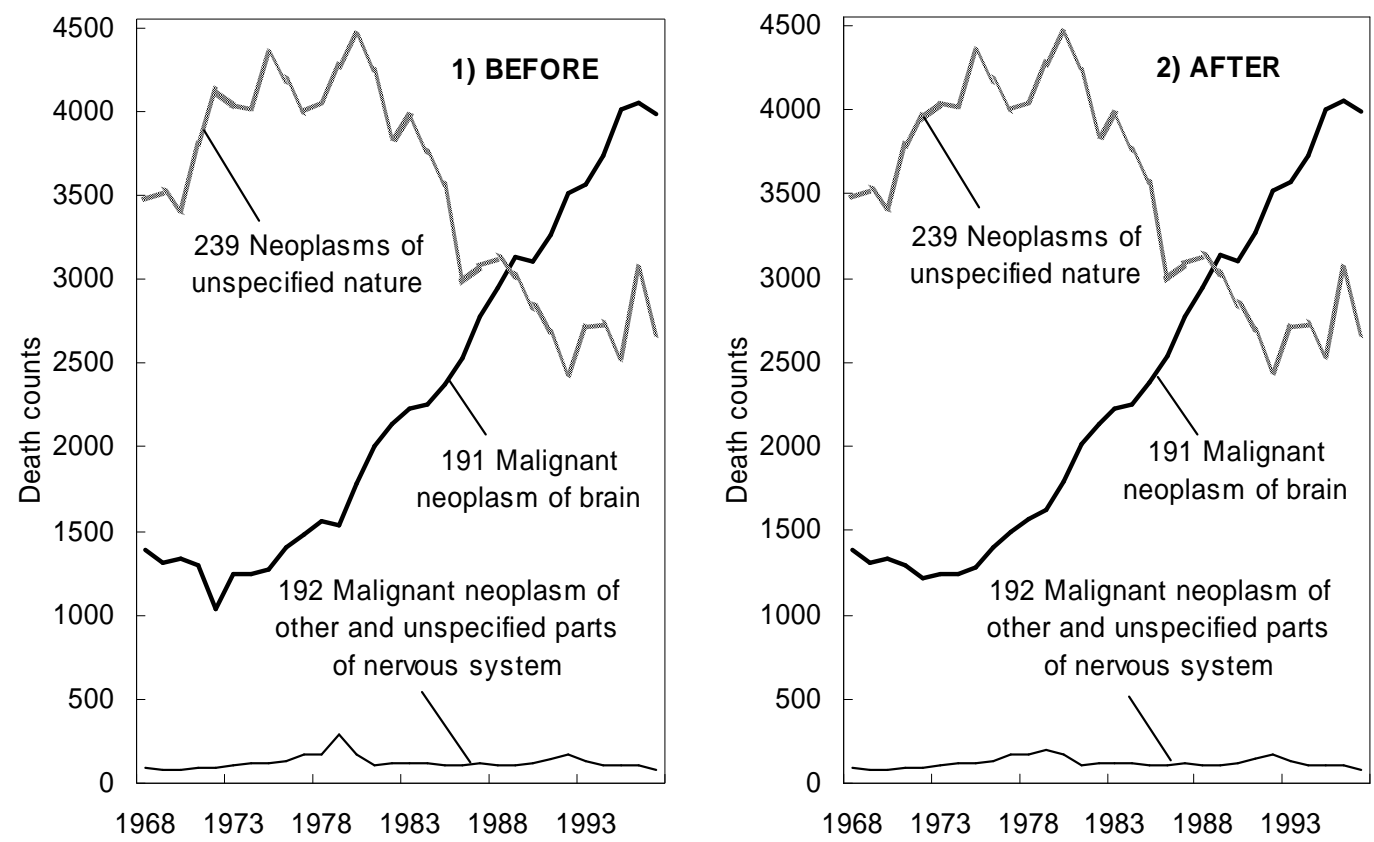

Figure 17 Number of deaths from ICD9 item $\mathrm{n}^{\circ} 191$ Malignant neoplasm of brain and ICD9 item $\mathrm{n}^{\circ} 192$ Malignant neoplasm of other and unspecified parts of the nervous system, before and after the correction a posteriori

A similar kind of exchange, again for year 1979, was required for ICD9 item $\mathrm{n}^{\circ} 427$, Cardiac disrhythmias and ICD9 item $\mathrm{n}^{\circ} 421$, Old myocardial infarction, transferring the deaths for age 35 and above (Figure 18).

Figure 19 shows a problem related to the adoption of the $8^{\text {th }}$ revision of ICD in 1968 . In the first two years following the classification switch, the tabulated data contained ICD9 item $n^{\circ} 486$, Pneumonia, organism unspecified, but no deaths were assigned to this category in 1968-1969. In 1970, the death counts suddenly passed from 0 to 11987, while the number of deaths classified under ICD9 item $\mathrm{n}^{\circ} 485$, Bronchopneumonia, organism unspecified, dropped from 17591 in 1969 to 6957 in 1970, perfectly coinciding with an increase in pneumonia of unspecified aetiological agens. The transfer thus logically concerned all age groups, with a greater exchange for early-life deaths (Table 9).

Table 9 summarizes all corrections applied to the German series a posteriori, by calendar year and age group. The changes concern a total of 20 ICD9 items and are all age-specific. 

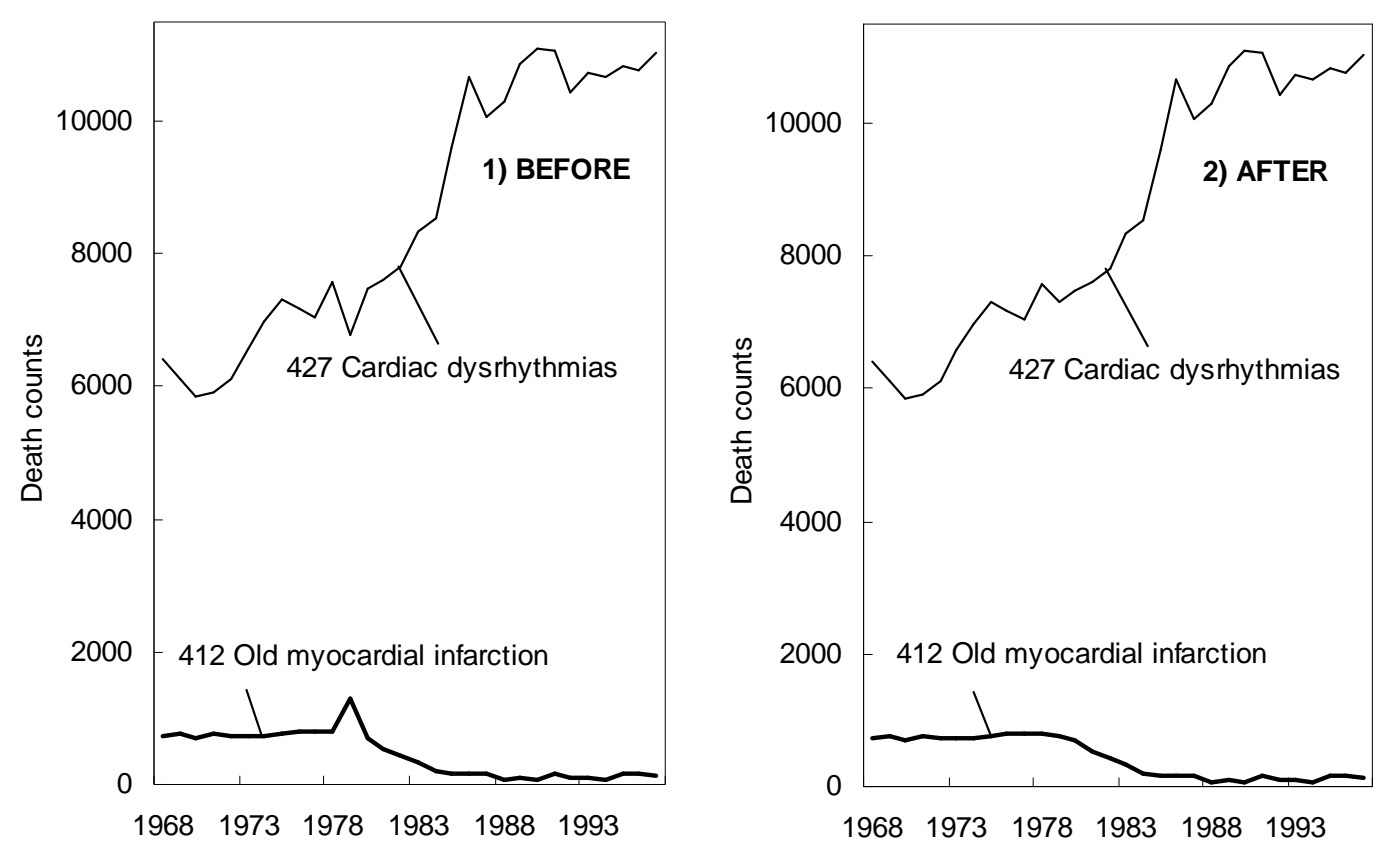

Figure 18 Number of deaths from ICD9 item $n^{\circ} 427$ Cardiac disrhythmias and ICD9 item $n^{\circ} 421$ Old myocardial infarction, before and after the correction a posteriori
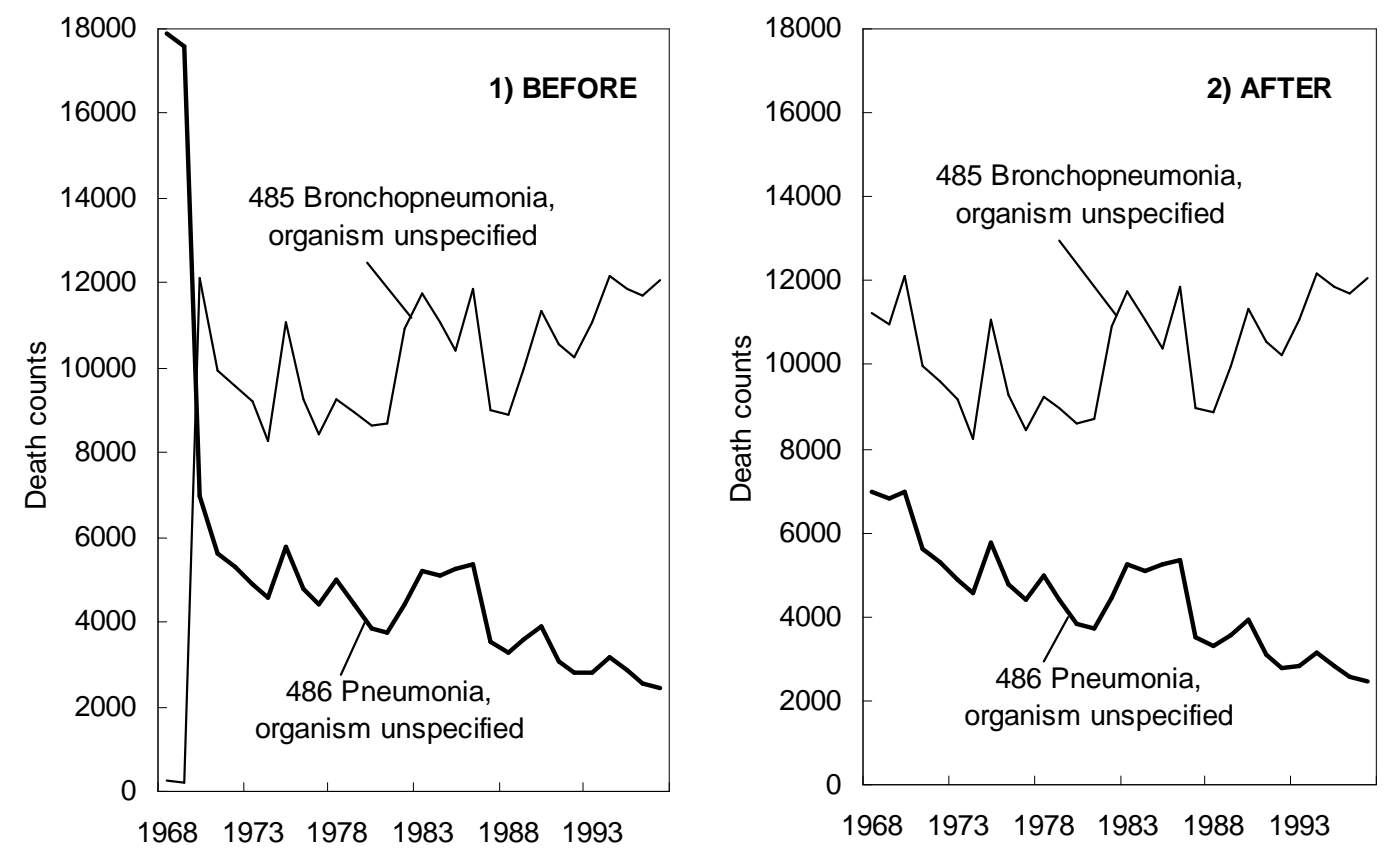

Figure 19 Number of deaths from ICD9 item $n^{\circ} 485$ Bronchopneumonia, organism unspecified and ICD9 item $n^{\circ} 486$ Pneumonia, organism unspecified, before and after the correction a posteriori 
Table 9 Percentages of exchange between ICD9 items in 1968-1997

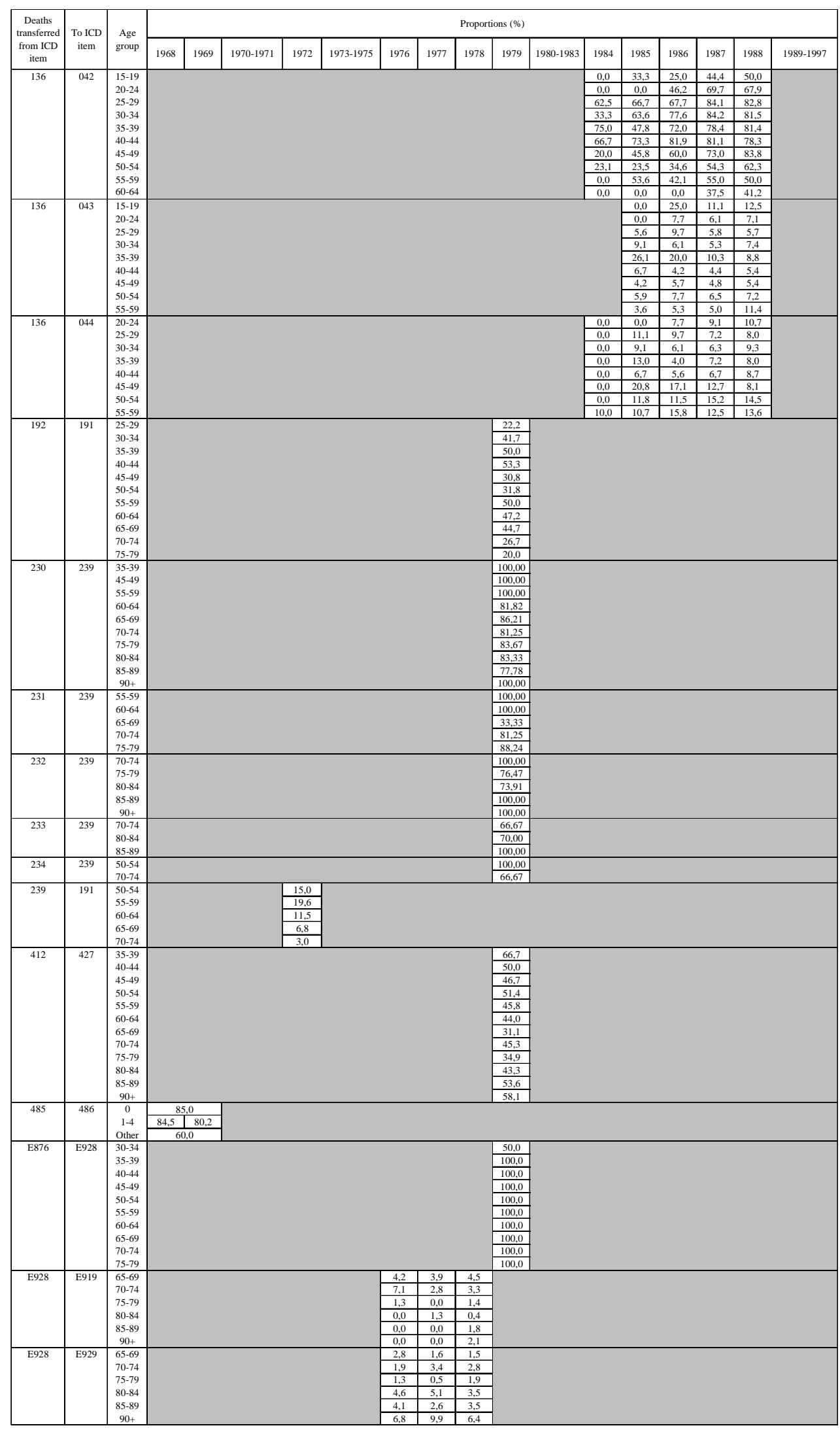


Nevertheless, in certain diseases the observed mortality trend does not always reflect the evolution of the disease itself, i.e. we cannot distinguish whether the rise or fall is the result of a real change in the disease incidence or rather a consequence of a spreading knowledge about the aetiology and the clinical course of the disease. The proportions of ill-defined causes, especially senility, have dropped significantly in the elderly over the 1968-1997 period (see Section 2.4.3). These deaths have obviously been classified under other items, of which the consequent rise is thus artificial. A well known case is ICD9 item $\mathrm{n}^{\circ} 331.0$, Alzheimer disease, practically unknown prior to the 1980s and quickly becoming a frequent cause of death in the elderly (Vallin, Meslé 1998). The available data for West Germany does not have the four digit detail, but the fact that the death counts in the whole three digit ICD9 item $\mathrm{n}^{\circ} 331$ Other cerebral degenerations rose from 508 in 1968 to 4111 in 1997 suggests that there is a similar tendency in West Germany, an artefact of increasing incidence in Alzheimer disease among the certifying practitioners. There is unfortunately no way to find out where the deaths classified currently under "Alzheimer disease" were placed before. By the same token, it is impossible to estimate how many deaths from this disease remain misclassified.

\subsubsection{The redistribution of ill-defined causes of death}

A final task remains, namely that of dealing with ill-defined causes of death. This step is necessary in order to eliminate the bias introduced by changing the proportions of ill-defined deaths in time, and to allow for a comparison between a greater number of countries with different proportions of ill-defined causes of death.

We have chosen to redistribute these deaths proportionally to well-defined diseases (001-779) and into accidents (E800-E999). The proportional method is fully applicable to West Germany, where the share of ill-defined deaths is relatively low, the era of epidemics has passed and the time series do not show any major fluctuations. Moreover, several redistribution methods (proportional and regression method inspired by Sully Ledermann [Ledermann 1955, cit. in Vallin, Meslé 1988]) were tested on West German data from 1981-1983 and the author concluded that the selection of the method has a minor impact on the redistribution result (Bubenheim 2000).

Applying the method of proportional redistribution, we assume that every death can be attributed a disease or an accident listed in ICD9 and, consequently, if the death, for some reason was not classified as ill-defined, it would have been classified under one of the ICD9 categories. At the same time, the method assumes that the decision whether the death is classified as ill-defined or not is independent of its real underlying cause (Bubenheim 2000). These assumptions are hardly true for age 0, where sudden infant deaths (especially ICD9 item $\mathrm{n}^{\circ}$ 798.0, Sudden infant death syndrome) still occur without a known cause and occupy an important position in infant mortality. Therefore, the deaths from item $n^{\circ} 798$ remain without redistribution for the first year of life.

\section{SUMMARY}

We have collected and computerised data from 1968 to 1997 , covering the $8^{\text {th }}$ and $9^{\text {th }}$ revision of the international classification of disease. The statistical continuity of the 
data was affected by changes in the tabulation system in 1969 and 1980, but these discontinuities are minor compared to the perturbances introduced at the time of amendments made to disease classification in 1979.

We have shown the way in which the primary information on cause of death from the medical certifier is transferred to the tables published by the provider of the data we work with, the federal statistical office in Wiesbaden, and highlighted regional differences in the West German burial law. From the results of the studies presented above we conclude that there are documented biases concerning West German causeof-death statistics. At the level of certification, diagnosis and reporting play different roles for different groups of causes of death. While the cardiovascular diseases seem to be overreported in death certificates, tabulated mortality due to cancer is strongly underestimated as a consequence of both underdiagnosing and underreporting by the certifying practitioners, the former probably having a much larger effect. However, once correctly diagnosed and reported, a tumour will appear correctly coded in the mortality statistics in more than $84 \%$ of the cases, while in the case of cardiovascular diseases the inter-coder agreement varies only between $60 \%$ and $80 \%$.

Implausible reported chains of pathologies or death certificate that are incompletely filled in and incorrectly coded, however, contribute only partially to the data unreliability. As the average age at death rapidly increases, a growing number of people die at very advanced age, where multiple degenerative diseases occur simultaneously. The determination of a single underlying cause of death in the elderly is thus problematic and might be ambiguous (Ruzicka 1990). The fatal outcome of arterial degeneration, considered a disease at younger age, can be a manifestation of the natural ageing processes in older subjects. However, old age as such (senility) should not be reported as a cause of death. The reconstructed data show that large progress was made in cause of death reporting in the elderly during the last three decades.

In a broader European context, German cause-of-death data are of a high quality due to compulsory post-mortem examination by medical doctors, centralized professional training, and a constant effort in the improvement of reporting the cause of death. However, low autopsy rates and experimental studies on completed death certificates show that there remains room for improving the reliability of cause-of-death data. Moreover, to better fulfil the needs of the public health sector in the demographically ageing society of West Germany, it is highly desirable to process all information given on death certificate (the multiple causes of death) and to extend the upper age limit of the published data. The centralized legislation possibly solves the problems of data quality arising from regional differences in the legal aspects of death and codification.

The next part of the study dealt with the process of reconstructing the time series itself. Although mainly focusing on the problems of double classification and the question of the medical content of the ICD categories, some of the issues mentioned in the data quality section of the present paper were be re-discussed and solved, namely the persistence of ill-defined conditions and the effect of sudden changes in the coding rules and practices on the time series.

All stages of reconstruction work were described in detail and accompanied by concrete examples of specific problems and applied solutions. Although the principles of the method can be universally applied (including countries not using ICD yet), the specific problems will vary from country to country due to persisting variance in 
reporting and coding manners. Obviously, these problems can be detected solely via a thorough inspection of the time series.

For the very first time, the presented method was applied on the level of 3-digit ICD items. In earlier works, the authors used either grouped items (United Kingdom, Netherlands), or the most detailed 4-digit level (France), or the transition was performed on a classification other than ICD (countries of ex-USSR). As the 3-digit level is the usual detail provided by the national statistical offices, the results of this work could serve as guidelines for future reconstruction attempts in other countries where the double codification at the time of classification change is missing.

This report is accompanied by the reconstructed mortality time-series for West Germany, including complementary data, and documentation. The death counts are given sorted by 3-digit ICD9 items, 5-year age groups and sex, after the redistribution of ill-defined causes of death. Age-specific death rates in the same level of detail are provided too. Finally, we have calculated the age-standardized death rates for each 3-digit ICD9 item, both before and after the redistribution of the ill-defined causes of death.

The complementary part of the Annex then contains the full documentation of the above described method and its outcomes: the ICD8 and ICD9 lists, the tables of elementary associations and transition coefficients, references to the data sources, detailed description of the data formats, and the population counts used for the calculations. 


\section{Acknowledgements}

This report, accompanied by the data published in the Annex, represents the first result of the project "Reconstruction of continuous time series of mortality by cause of death in West Germany", launched in the Laboratory for the Demographic Data at the Max Planck Institute for Demographic Research in June 2000.

Several researchers were intensively involved in this project. The data were meticulously collected, checked and documented by Sigrid Gellers-Barkmann, Michael Bubenheim, and Rembrandt Scholz, assisted by a team of students at the MPIDR. Michael Bubenheim elaborated the systematic comparison between the items of ICD8 and ICD9, adapted the correspondences to the West German data, and prepared the first version of the elementary associations. The author is also grateful to Vladimir Shkolnikov and Rembrandt Scholz for valuable comments and efficient support.

The author wishes to express very special thanks to France Meslé and Jacques Vallin from INED (Institut National d'Études Démographiques), who were continuously consulting the results of the work and reviewed the interim version of this report.

Apart from the research institutes involved in this project, the author would like to acknowledge the European Commission for launching the research training network (RTN) coordinated by the MPIDR (Network Title: Demographic Sustainability and European Integration; Contract Number: HPRN-CT-2001-00234), which enabled the author to work for several months at INED and to accomplish a major part of the reconstruction work, under the supervision of France Meslé and Jacques Vallin.

Last, but not least, the author would like to acknowledge Susann Backer for language editing and bringing the document linguistically up to a stage at which it could be published. 


\section{REFERENCES}

Andreev K. F. (1999) Demographic surfaces: Estimation, Assessment and Presentation, with application to Danish Mortality, 1835-1995. Ph.D. thesis. University of Southern Denmark.

Ärztekammer Nordrhein, Neue Todesbescheinigung NRW zum 1. Juli 2001 eingeführt/Alte Todesbescheinigungen können bis zum 31.12.2001 verwendet werden, Rheinisches Ärzteblatt 8/2001

Barbieri M. (1998) La mortalité infantile en France. Population 53(4), p. 813-838

Becker N., Wahrendorf J. (1998) Krebsatlas der BundesrepublikDeutschland/Atlas of cancer mortality in Germany. 3 ed Berlin, Heidelberg, New York: Springer

Brinkmann B., Du Chesne A., Vennemann B. (2002) Aktuelle Daten zur Obduktionsfrequenz in Deutschland, Deutsche med Wochenschrift; 127, p. 791795

Bubenheim M. (2000) Des systèmes d'enregistrement des décès par cause en France et en Allemagne (PhD dissertation, Université Lumière, Lyon 2)

Centers for Disease Control (CDC) (1987) Human Immunodeficiency Virus (HIV) Infection Codes: Official Authorized Addendum ICD-9-CM Effective January 1, 1988. Morbidity and Mortality Weekly Report, 36 (No. S-7, p. 1-24)

Freistaat Bayern Todesbescheingung, Information für die Ärztin/den Arzt, http://www.blaek.de/pdf_rechtliches/extra/todesbe.pdf

ISTAT (2003) Manual on certification of causes of death in Europe. Rome, EUROSTAT - ISTAT Contract $N^{\circ} 200235100007$

Jahn I., Jöckel K.H., Bocter N., Müller W. (1995) Studie zur Verbesserung der Validität und Reliabilitätder amtlichen Todesursachenstatistik.Schriftenreihe des BMG Band 25, ISBN 3-7890-3954-3

Jakob R., Schopen M. (2004) Mortalitätsverschlüsselung mit der ICD-10. Schulung der Signierer in den statistischen Landesämtern und in den Hamburger Gesundheitsämtern (presentation) 
Lee P.N. (1994) Comparison of autopsy, clinical and death certificate diagnosis with particular reference to lung cancer. A review of the published data. APMIS Suppl. 45, 102, 3-42.

Leitner B. (2004): Qualitätsaspekte der Todesursachenstatistik. Ergebnisse einer Vergleichskodierstudie ICD-9 und ICD-10. In: Statistische Nachrichten 59,8, p. 735-741.

Madea B., Dettmeyer R. (2003) Ärztliche Leichenschau und Todesbescheinigung. Deutsch Ärzteblatt; 100:A 3161-3179 [48].

Meslé F. (1995) L'enregistrement des causes de décès en Europe, in : Josianne Duchêne et Guillaume Wunsch (éd.), Collecte et comparabilité des données démographiques et sociales en Europe, p. 401-431. - Louvain-la-Neuve, Academia/L'Harmattan, $671 \mathrm{p}$.

Meslé F., Shkolnikov V., Hertrich V., Vallin J. (1996) Tendances récentes de la mortalité par cause en Russie, 1965-1994. Paris, INED, 140 p.

Meslé F., Vallin J. (1993) Causes de décès : de la 8e à la 9e révision, deux cas différents, la France et l'Angleterre, in: Alain Blum et Jean-Louis Rallu (eds.), Démographie européenne. II. Dynamiques démographiques, p. 421-445. - Paris, John Libbey/INED

Meslé F., Vallin J. (2003) Mortalité et causes de décès en Ukraine au XXe siècle. Cahier n 152,422 p. + CD-Rom, INED, PUF, Paris

Modelmog D., Rahlenbeck S., Trichopoulos D. (1992) Accuracy of death certificates: a population-based, complete-coverage, one-year autopsy study in East Germany. Cancer Causes Control. Nov;3(6), p. 541-546.

Müller W., Bocter N. (1990) Beitrag zur Abschätzung der Aussagekraft der amtlichen Todesursachenstatistik - Eine empirische Untersuchung zur Verbesserung der Validität. Schriftenreihe des Bundesministeriums für Jugend, Familie, Frauen und Gesundheit, Band 253, Verlag W. Kohlhammer Stuttgart Berlin Köln. 
Office of Population Censuses and Surveys (1983) Mortality Statistics: comparison of $8^{\text {th }}$ and $9^{\text {th }}$ revisions of the International Classification of Diseases, 1978 (sample). London, OPCS, Series DN1, No. 10, 112p.

Ruzicka L.T., Lopez A.D. (1990) The use of cause of death statistics for health situation assessment: national and international experiences. World Health Statistics Quarterly 1990; 43: 249-258.

Schellscheidt J., Ott A., Jorch G. (1997) Epidemiological features of sudden infant death after a German intervention campaign in 1992. European Journal of Pediatrics Volume 156, Number 8, p. 655 - 660

Schopen M., Dittrich S. (2002) EDV-basierte Kodierung der Todesursachen. Ein Weg zu einer besseren Mortalitätsstatistik? Presentation at Fachtagung EDV im Öffentlichen Gesundheitsdienst, 19. 3. 2002, Düsseldorf http://www.dimdi.de/static/de/dimdi/public/vortraege/scho0302.pdf

Statistisches Bundesamt (2005) Grundlagen der Todesursachenstatistik. http://www.destatis.de/download/gesu/totesurs.pdf

Vallin J., Meslé F. (1987) Les causes de décès en France de 1925 à 1978: reclassement selon la $8^{\text {ème }}$ révision de la Classification internationale, 2. Résultats du reclassement. Paris, INED, PUF, 608 p. (Travaux et documents, annexe V du cahier 115).

Vallin J., Meslé F. (1988) Les causes de décès en France de 1925 à 1978 - Paris, INED,PUF, 608 p., avec Étude des variations géographiques, par Graziella Caselli et Viviana Egidi; préface de Jean Bourgeois-Pichat. (Travaux et Documents, Cahier 115).

Vallin J., Meslé F. (1998) Comment suivre l'évolution de la mortalité par cause malgré les discontinuités de la statistique ? Le cas de la France de 1925 à 1993, in : Gérard Pavillon (ed.), Enjeux des classifications internationales en santé, p. 113-156. - Paris, Éditions INSERM, 220 p. (Questions en santé publique).

WHO (1986) International Classification of Diseases, Ninth Revision. Clinical Modification. Vol. 1 and 2 update. (HTLV-III/LAV Infection codes. Official Authorized Addendum. Geneva, World Health Organization, 20 p. 
Wolleswinkel-van Den Bosch J.H., Van Poppel F.W., Mackenbach J.P. (1996) Reclassifying causes of death to study the epidemiological transition in the Netherlands,1875-1992. Eur J Popul. 1996 Dec;12(4):327-61. 


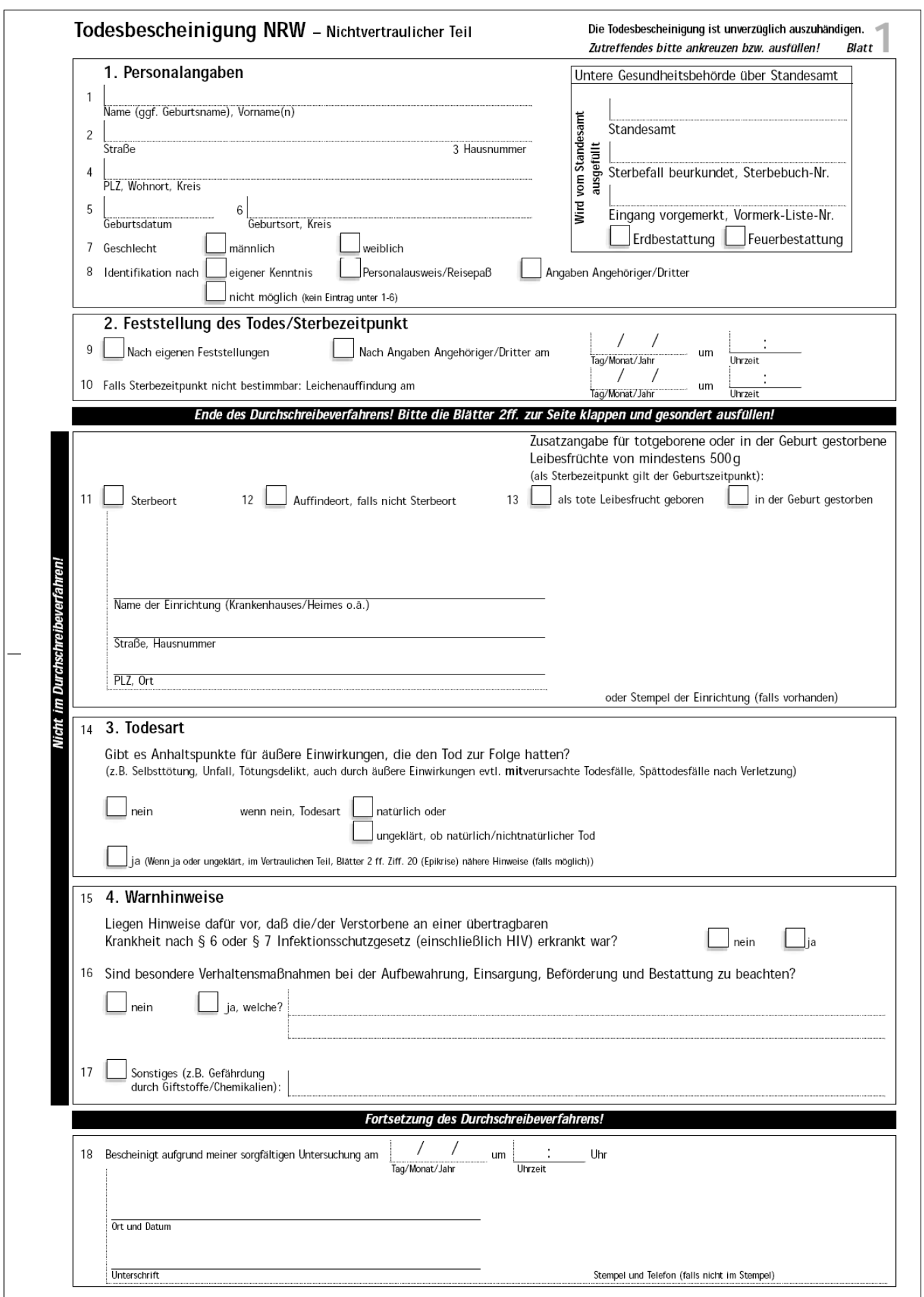

Appendix 1a Death certificate (Todesbescheinigung) in North-Rhine-Westphalia: non-confidential section

Source: Rheinisches Ärzteblatt 8/2001 


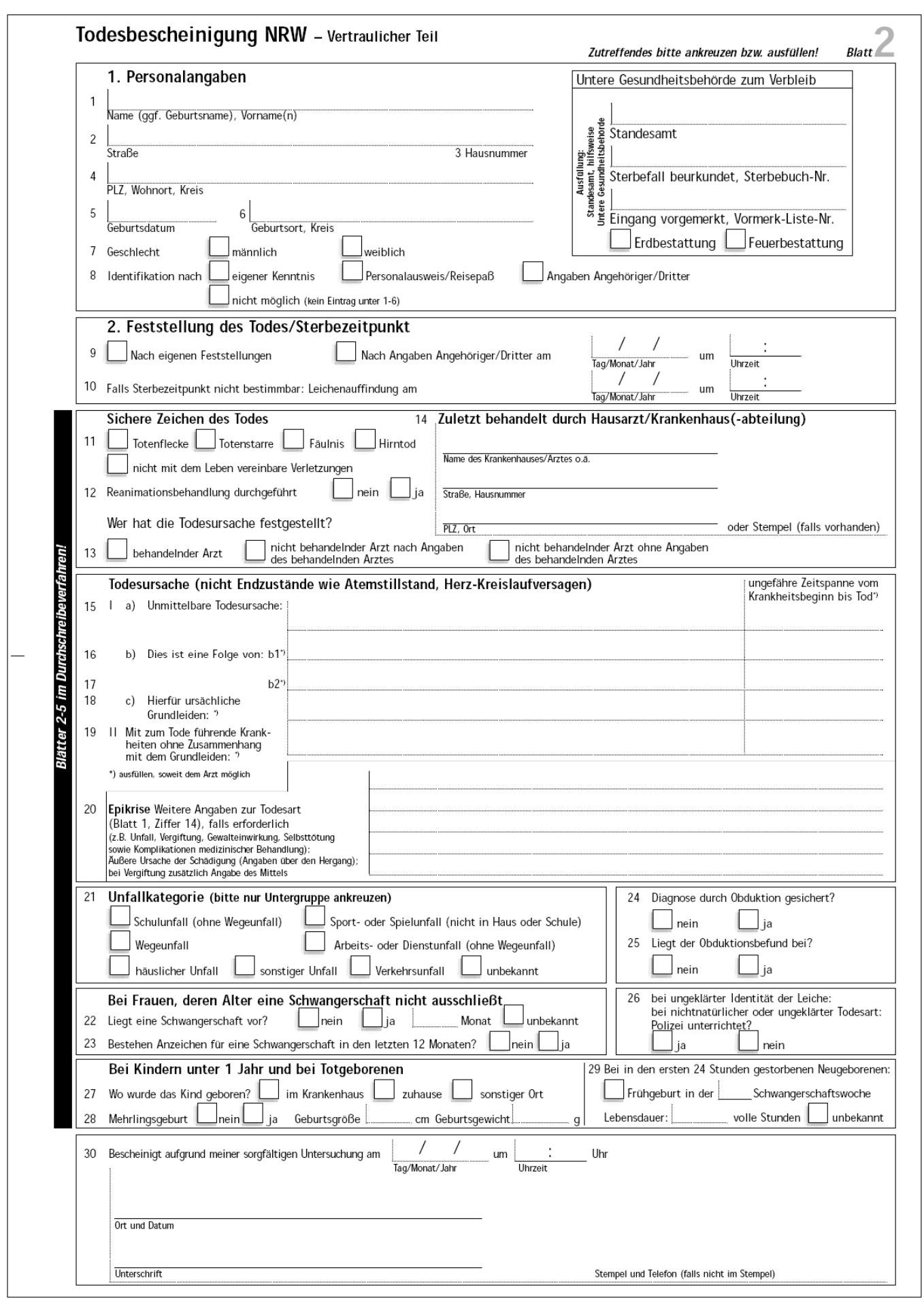

Appendix 1b Death certificate (Todesbescheinigung) in North-Rhine-Westphalia: confidential section

Source: Rheinisches Ärzteblatt 8/2001 


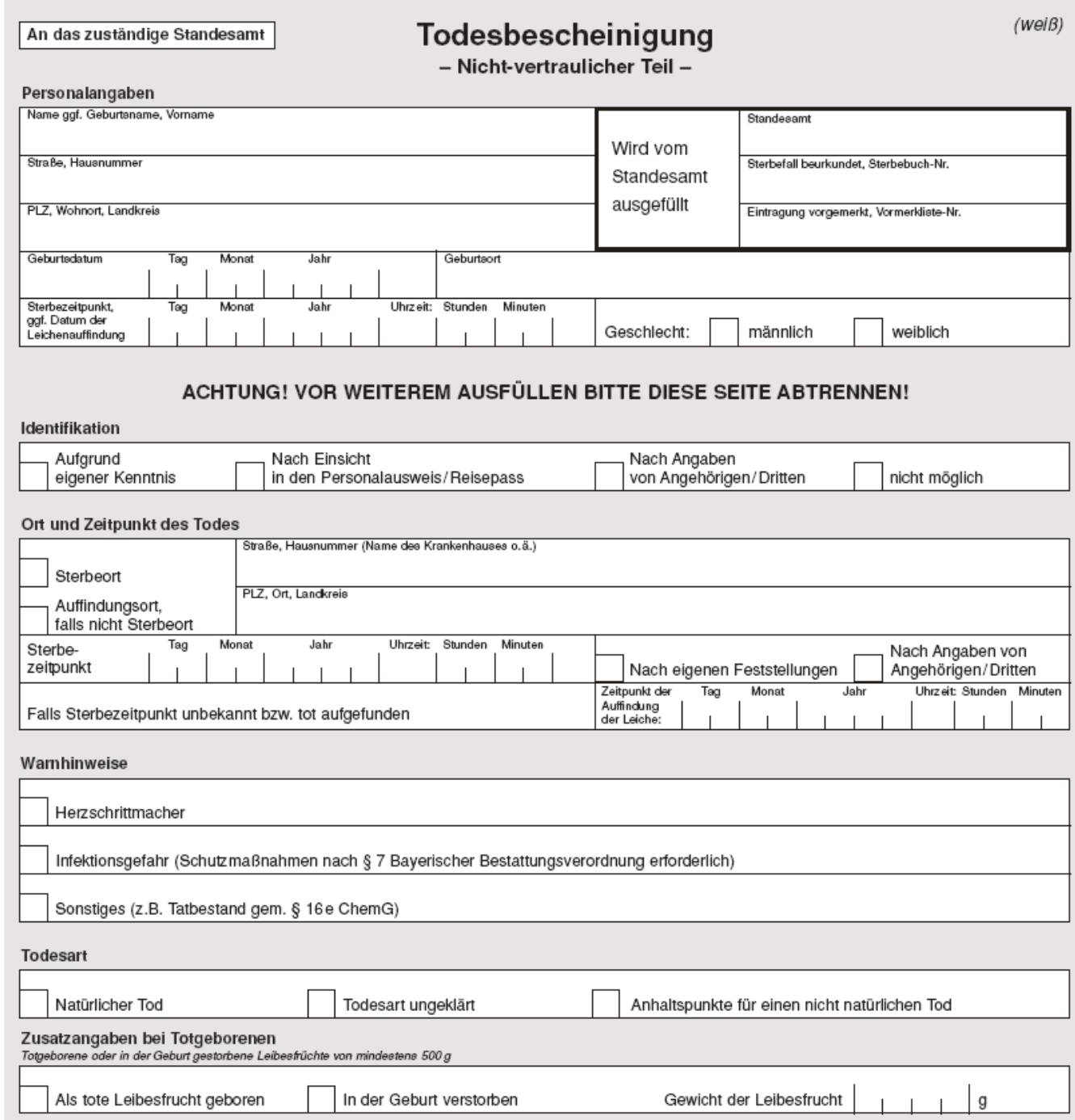

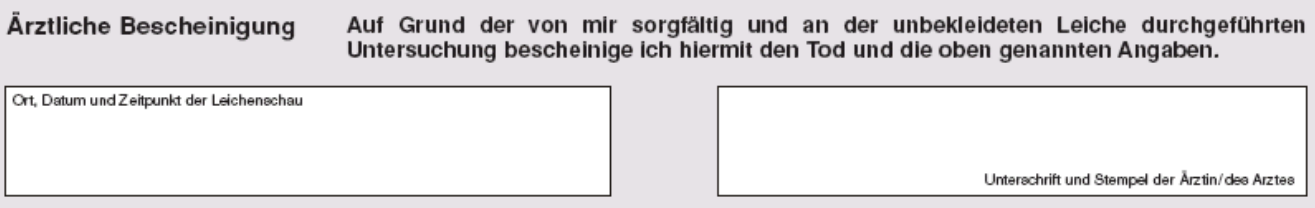

\section{Appendix 2a Death certificate (Todesbescheinigung) in Bavaria: non-confidential section}

Source: Freistaat Bayern Todesbescheingung, Information für die Ärztin/den Arzt,

http://www.blaek.de/pdf_rechtliches/extra/todesbe.pdf 


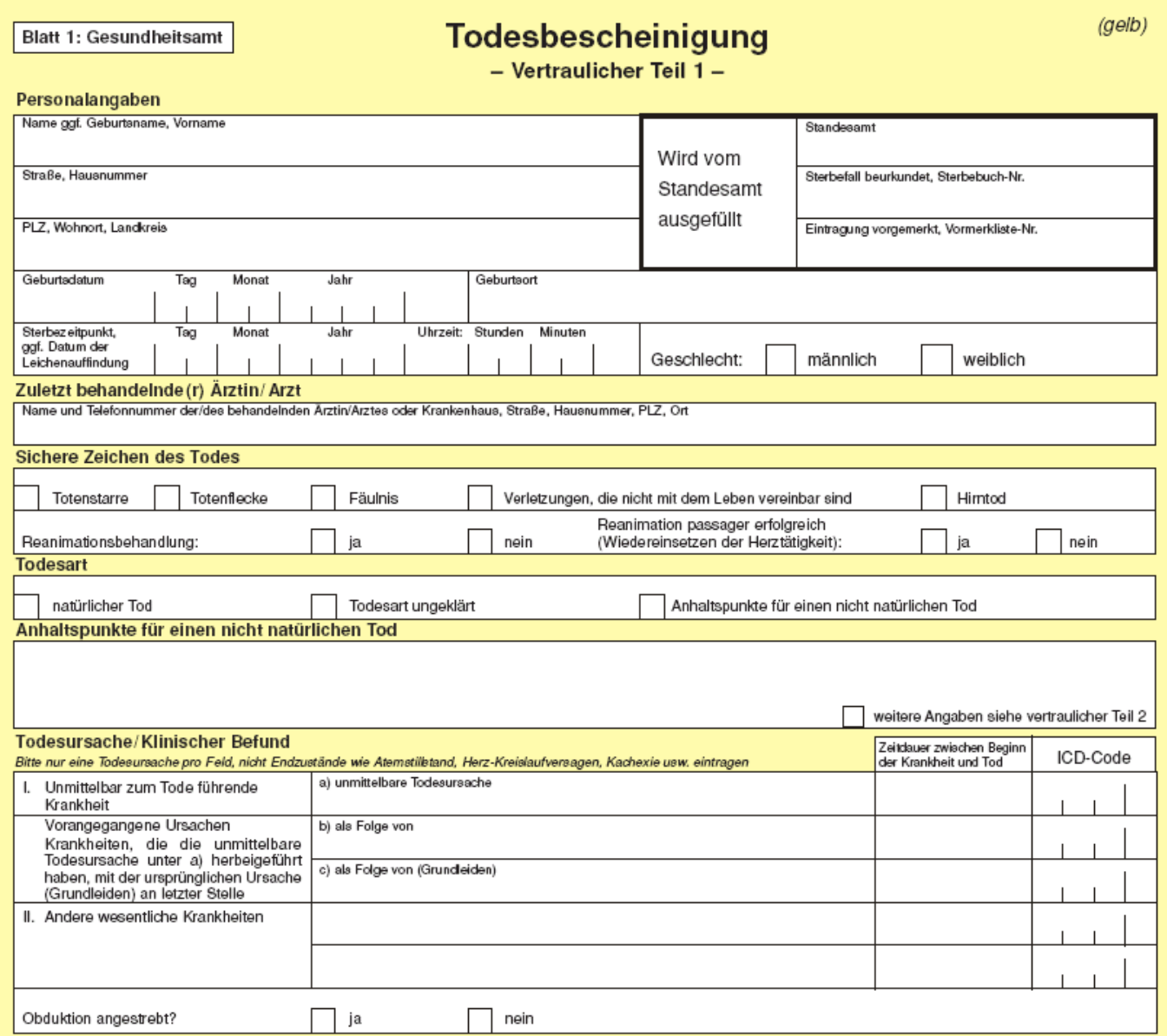

Angaben zur Todesursache und zu Begleiterkrankungen (Epikrise)

\begin{tabular}{|c|c|c|c|c|}
\hline \multirow{2}{*}{\multicolumn{5}{|c|}{ aben zur Klassifikation der Todes }} \\
\hline \multirow{3}{*}{\begin{tabular}{|l|} 
Z.B. bei Unfall, Vergiftung, Gewalteinwir- \\
kung, Selbstittung sowie beil Kompli- \\
kationen medizinischer Behandlung
\end{tabular}} & \multirow{2}{*}{\multicolumn{3}{|c|}{ AuB Bere Ureache der Schádigung (Amabenen über den Hergang) }} & \\
\hline & & & & ICD-Code \\
\hline & \multicolumn{3}{|l|}{ Bei Vergiftung: Angabe dee Mittele } & \\
\hline \multirow[t]{2}{*}{$\begin{array}{l}\text { Unfallkategorie } \\
\text { (bitte nur eine Untergruppe ankreuzen) }\end{array}$} & $\begin{array}{l}\text { Arbeits- oder Dienstunfall } \\
\text { (ohne Wegeuntall) }\end{array}$ & \multicolumn{2}{|c|}{$\begin{array}{l}\text { Arbeits- oder Dienstunfall } \\
\text { (ohne Wegeunfall) }\end{array}$} & $\square$ Verkehrsunfall \\
\hline & \multicolumn{3}{|l|}{$\square$ häuslicher Unfall } & $\begin{array}{l}\text { Sonstiger } \\
\text { Unfall }\end{array}$ \\
\hline \begin{tabular}{|l} 
Bei Kindern unter einem Jahr sovie bei \\
Totgeburten
\end{tabular} & Mehrlingsgeburt? $\square$ ja $\square$ nein & Lảnge bei Geburt & ewicht & \\
\hline $\begin{array}{l}\text { Bei Neugeborenen, die innerhalb } \\
\text { der ersten } 24 \text { Stunden verstorben sind }\end{array}$ & $\begin{array}{l}\text { Frühgeburt } \\
\text { in der }\end{array}$ & rschaftswoche & $\begin{array}{l}\text { Lebenendauer in volendeten Stunden } \\
\text { | Stunden }\end{array}$ & \\
\hline \multirow[t]{3}{*}{ Bei Frauen } & \multicolumn{2}{|l|}{ Liegt eine Schwangerschaft vor? } & $-\tan$ Monat $\square$ nein & $\square$ unbekannt \\
\hline & \multicolumn{3}{|c|}{$\begin{array}{l}\text { Erfolgtte in den letzten } 42 \text { Tagen eine Entbindung, eine } \\
\text { Interruptio, ein Abort oder eine Extrauteringravidititä? }\end{array}$} & unbekannt \\
\hline & \multicolumn{3}{|c|}{$\begin{array}{l}\text { Erfolgte zwischen dem 43. Tag und dem Beginn des letzten Jahres vor Todeseintritt eine Entbindung } \\
\text { eine Interruptio, ein Abort oder eine Extrauteringravidität? }\end{array}$} & \\
\hline
\end{tabular}

Ärztliche Bescheinigung Auf Grund der von mir sorgfältig und an der unbekleideten Leiche durchgeführten Untersuchung bescheinige ich hiermit den Tod und die oben genannten Angaben.

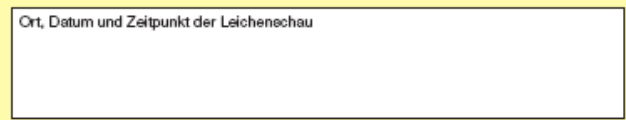

Unterechrift und Stempel der Ärtin/de日 Arzte日

\section{Appendix 2b Death certificate (Todesbescheinigung) in Bavaria: confidential section, part 1}

Source: Freistaat Bayern Todesbescheingung, Information für die Ärztin/den Arzt,

http://www.blaek.de/pdf_rechtliches/extra/todesbe.pdf 
Personalangaben

- Vertraulicher Teil 2-

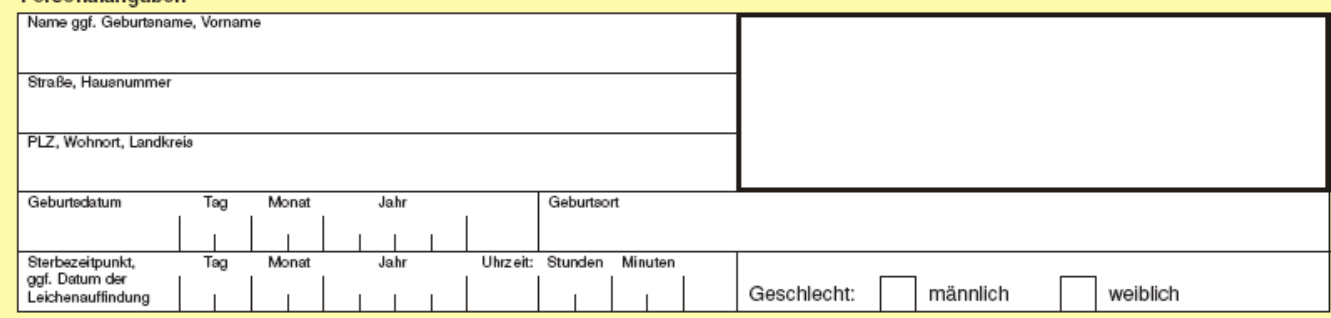

Der vertrauliche Teil 2 der Todesbescheinigung gibt der Ärztin/dem Arzt die Möglichkeit, ergänzende Anhaltspunkte für einen nicht natūrlichen Tod anzuführen und ergānzende Angaben zur Todesursache bzw. zu Begleiterkrankungen (Epikrise) zu machen. Bei Ausfūllen des vertraulichen Teils 2 bitte im vertraulichen Teil 1 ankreuzen, dass weitere Angaben gemacht werden. Auch der vertrauliche Teil 2 ist unter Angabe von Ort, Datum und Zeitpunkt der Leichenschau von der Ärztin/dem Arzt zu unterschreiben.

Der vertrauliche Teil 1 ist in jedem Falle vollständig auszufüllen!

Anhaltspunkte für einen nicht natürlichen Tod

Ergänzende Angaben zur Todesursache und zu Begleiterkrankungen (Epikrise)

Ärztliche Bescheinigung Auf Grund der von mir sorgfältig und an der unbekleideten Leiche durchgeführten Untersuchung bescheinige ich hiermit den Tod und die oben genannten Angaben.

Ort, Datum und Zeitpunkt der Leichenøchau

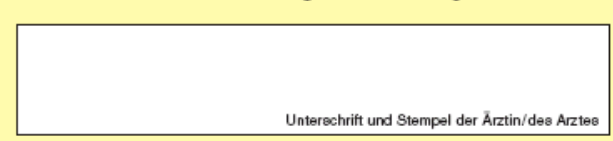

Appendix 2c Death certificate (Todesbescheinigung) in Bavaria: confidential section, part 2 (complementary information about violent deaths and comorbidity)

Source: Freistaat Bayern Todesbescheingung, Information für die Ärztin/den Arzt,

http://www.blaek.de/pdf_rechtliches/extra/todesbe.pdf 


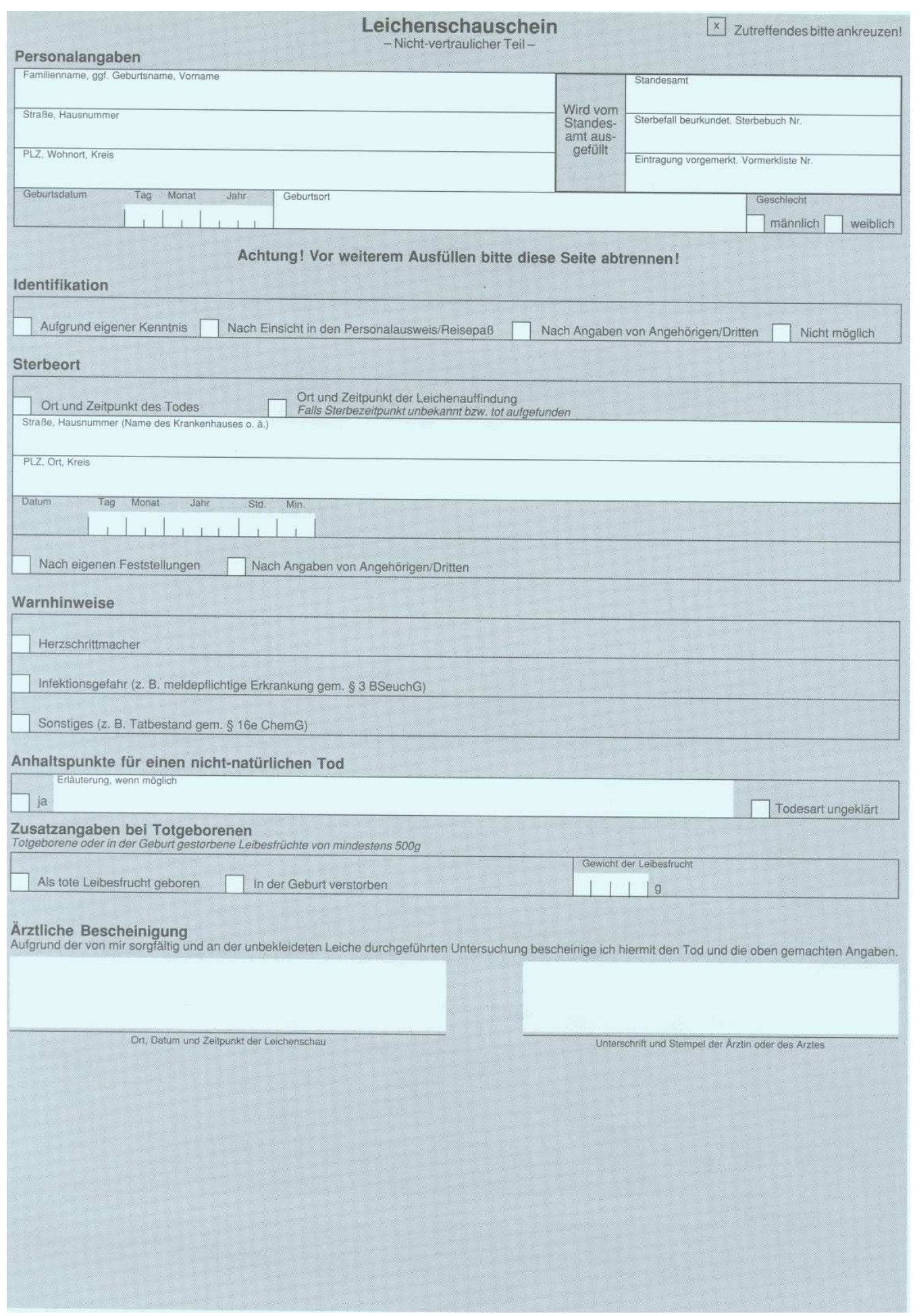

Appendix 3a Death certificate (Leichenschauschein) in Hesse: non-confidential section

Source: Verlag für Standesamtwesen GmbH, Frankfurt am Main, 2005 


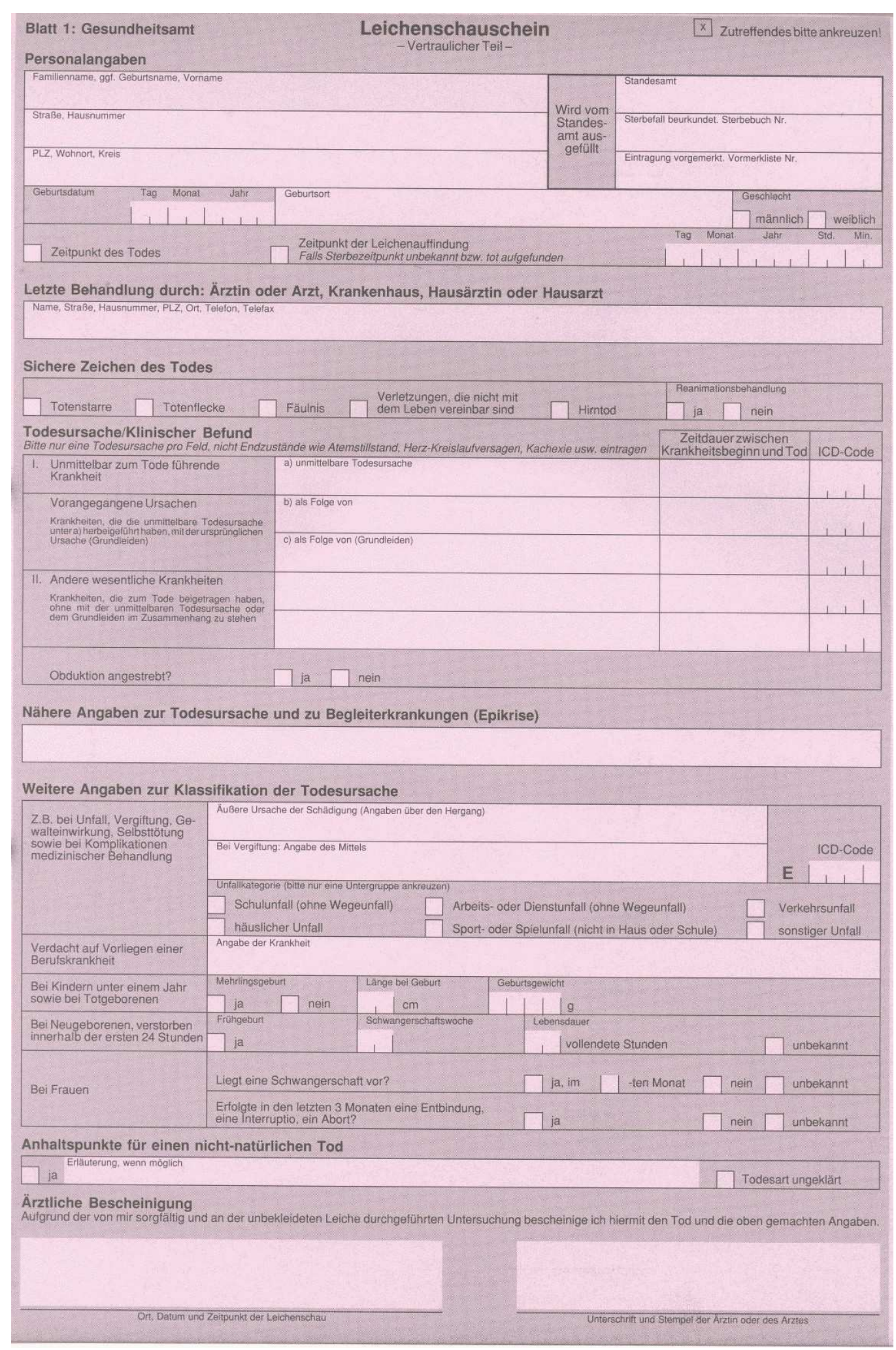

\section{Appendix 3b Death certificate (Leichenschauschein) in Hesse: confidential section}

Source: Verlag für Standesamtwesen GmbH, Frankfurt am Main, 2005 


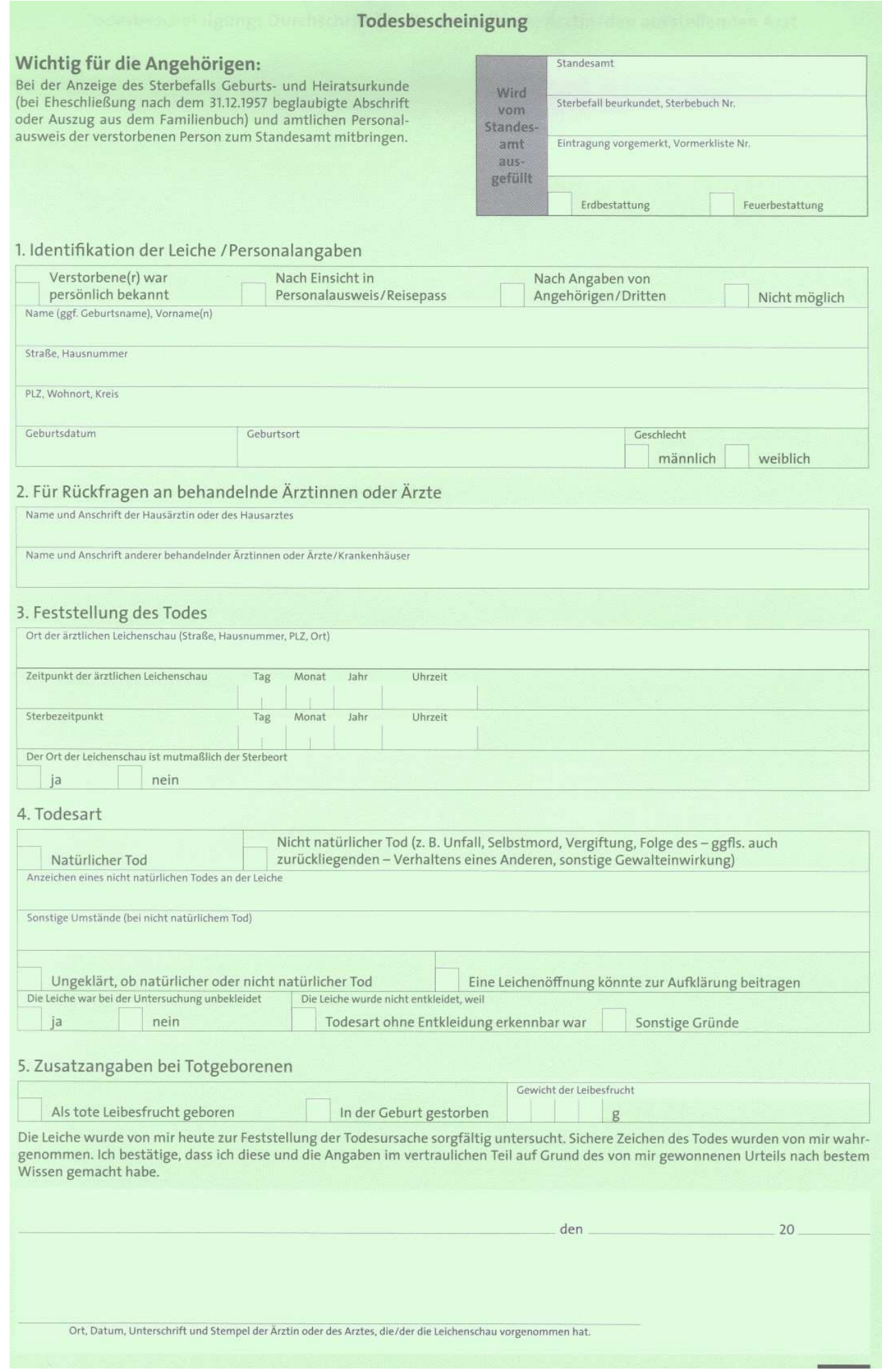

Appendix 4a Death certificate (Todesbescheinigung) in Lower Saxony: non-confidential section Source: Verlag für Standesamtwesen GmbH, Frankfurt am Main, 2005 


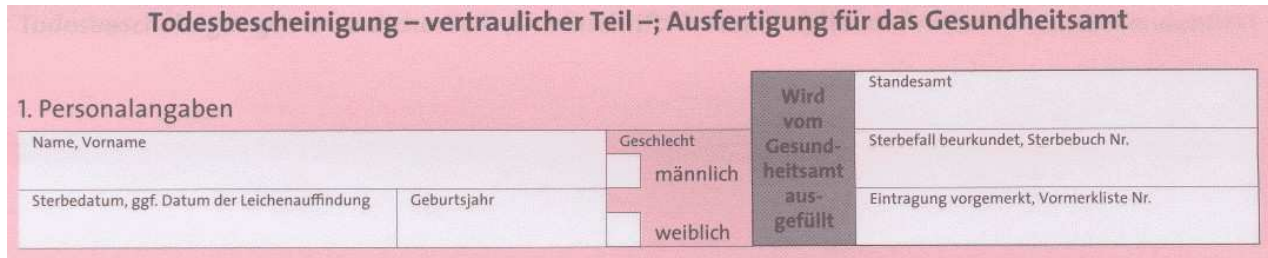

2. Nähere Angaben zur Todesursache und zu anderen wesentlichen Krankheiten (Epikrise)

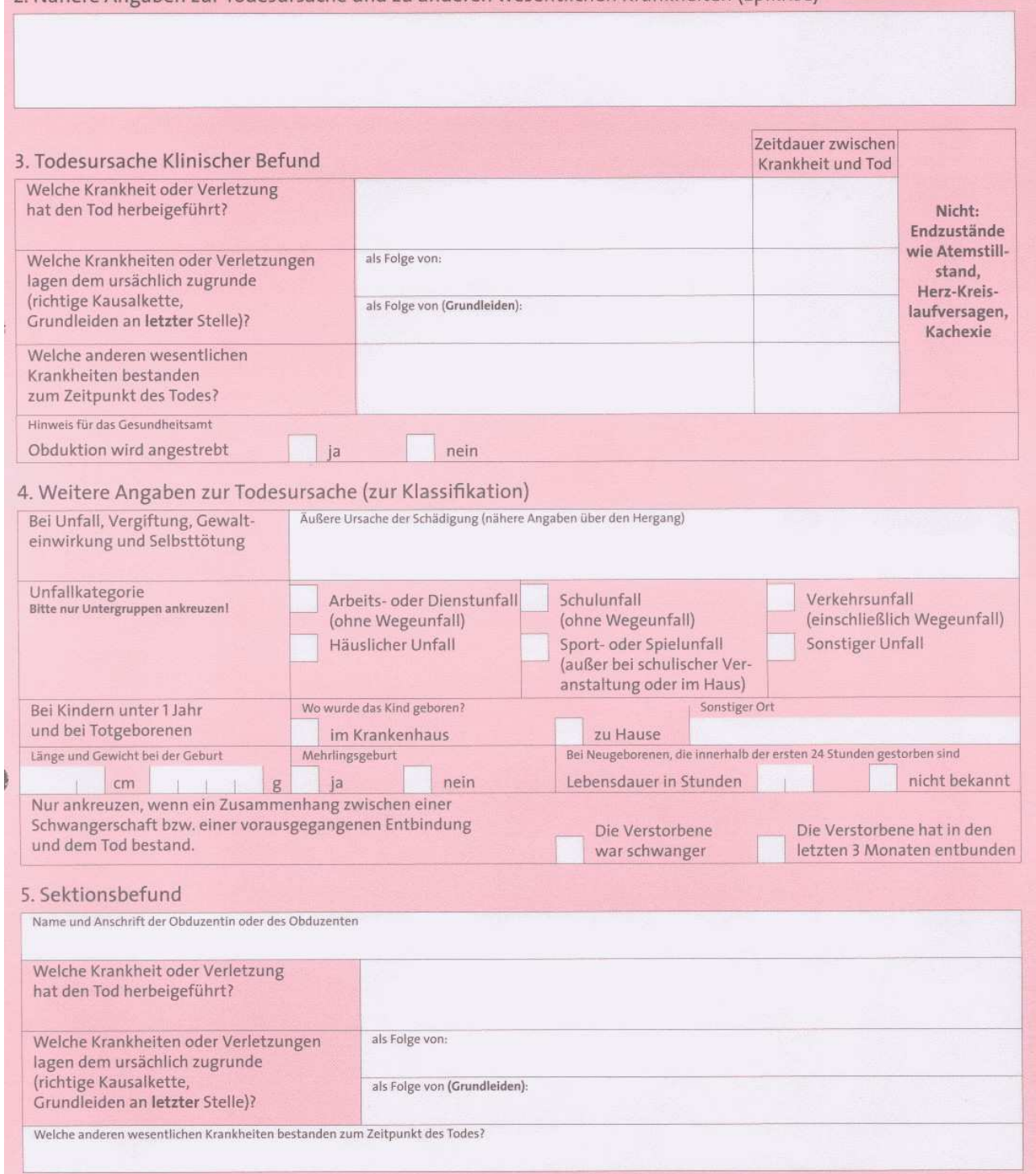

\section{Appendix 4b Death certificate (Todesbescheinigung) in Lower Saxony: confidential section}

Source: Verlag für Standesamtwesen GmbH, Frankfurt am Main, 2005 
$\underline{\mathrm{Nr} .}$

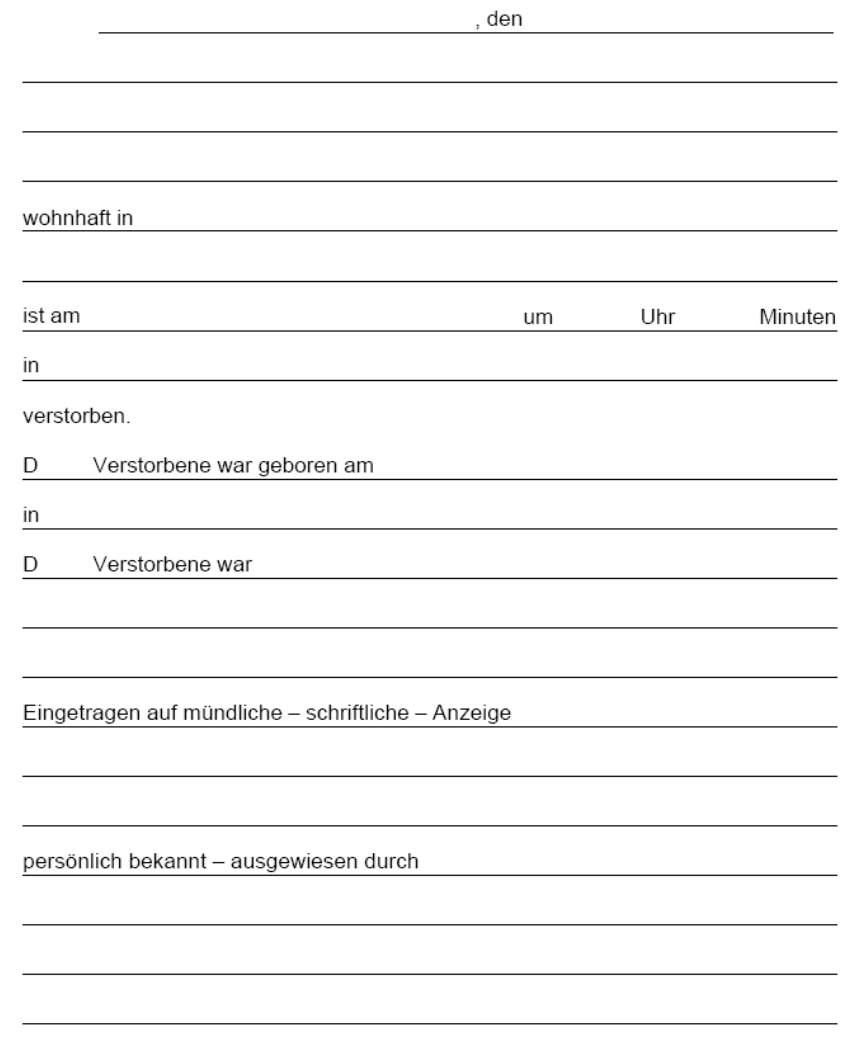

Vorgelesen, genehmigt und unterschrieben

\begin{tabular}{lll} 
& & \\
\hline
\end{tabular}

\section{Appendix 5 German death record}

Source: Verlag für Standesamtswesen GmbH, Frankfurt am Main, 2005 